\title{
Influence of lignocellulosic substrate and phosphorus flame retardant type on grafting yield and flame retardancy
}

\author{
Raymond Hajj $^{\mathrm{a}, \mathrm{b}, \mathrm{c}}$, Roland El Hage ${ }^{\mathrm{a}, \mathrm{c}, *}$, Rodolphe Sonnier ${ }^{\mathrm{b}, *}$, Belkacem Otazaghine ${ }^{\mathrm{b}}$, \\ Sophie Rouif ${ }^{\mathrm{d}}$, Michel Nakhl ${ }^{\mathrm{a}, \mathrm{c}}$, José-Marie Lopez-Cuesta ${ }^{\mathrm{b}}$ \\ ${ }^{a}$ LCPM, Faculty of Sciences, Lebanese University, Fanar, Lebanon \\ ${ }^{\mathrm{b}}$ Polymers Composites and Hybrids (PCH), IMT Mines Ales, Ales, France \\ ${ }^{\mathrm{c}}$ Platform for Research in Nanosciences and Nanotechnology, Lebanese University, EDST, Lebanon \\ ${ }^{\mathrm{d}}$ Ionisos SA, Dagneux, France
}

\begin{abstract}
A B S T R A C T
Various phosphorus flame retardants (FR) have been grafted on lignin-rich miscanthus fibers and lignin-poor flax fibers according to two methods, phosphonic acids condensation in mild conditions and radiation grafting. Phosphorus content and its location on fibers were evaluated. Even if phosphorus FR diffused into the fibers bulk in all cases, chemical modification based on phosphonic acids condensation with hydroxyls of miscanthus fibers appears more suitable for high lignin content fibers. Phosphorus content in miscanthus fibers reached $1.4 \mathrm{wt} \%$ using hexane-1,6-diylbisphosphonic acid whereas it reached a lower content $(0.3 \mathrm{wt} \%)$ for flax fibers. Radiation grafting is suitable for both fibers with limited effect depending on fiber nature. Flame retardancy at microscale was examined using PCFC and TGA. Thermal properties and flame retardancy have been shown to be correlated to the phosphorus content but also to fibers composition and to the thermal stability of the flame retardant. Vinyl phosphonic acid was found to be more efficient as char promoter for flax compared to miscanthus.
\end{abstract}

\author{
Keywords: \\ Miscanthus \\ Flax \\ Chemical modification \\ Radiation grafting \\ Phosphorus flame retardant
}

\section{Introduction}

Natural fibers have interested the textile industry for centuries [1]. More recently, they were found to be suitable alternatives to replace synthetic reinforcements as glass and carbon fibers in composite applications [2-4]. Many attractive advantages have been reported in literature as renewability, biodegradability, good availability, low cost, low density, non-toxicity, low abrasiveness (compared to fiberglass) and good mechanical properties [3,5-9]. However, their flammability remains a main drawback [10-13].

Natural fibers are mainly composed of cellulose, hemicelluloses and lignin [14]. A lower lignin content in natural fibers contributes to higher decomposition temperatures but lower oxidation resistance which is imparted by the aromatic structure of the lignin $[10,11]$. It has been reported that natural fibers with low cellulose (less than 49\%) and high lignin contents (more than 23\%) as coir and deciduous wood fibers have lower flammability than, for example, cotton with higher cellulose content (85-90\%) [11].

Flame retardancy of natural fibers has been improved using many techniques such as UV irradiation [15-17], plasma treatment [18], solgel treatment [19], gamma or e-beam irradiation [20-26].
Modification processes appear to be dependent from many factors as the fiber's composition and structure, the affinity of the solvent (if any) with the fiber, the accessibility of the molecule into the fiber's bulk, etc. [20-22,26-28].

Furthermore, the inhibitory effect of lignin has been studied by Sharif et al. [29]. Kenaf fibers were delignified with sodium chlorite solution $\mathrm{NaClO}_{2}$ before radiation grafting. The fibers were then preirradiated by e-beam radiation and immersed in water - glycidyl methacrylate (GMA) emulsion and heated under an inert atmosphere. The results indicate that lignin removal is necessary to improve GMA grafting onto kenaf fibers. The delignification process also modifies the hydrophobicity of kenaf fibers, which become more hydrophilic due to the cleavage and elimination of phenolic compounds. This allows the monomer to penetrate more easily into the kenaf fibers for grafting reaction.

Mohamed et al. [30] also studied the inhibitory effect of lignin with kenaf fibers. The kenaf fibers were delignified with sodium chlorite solution $\mathrm{NaClO}_{2}$ before radiation grafting. These fibers were e-beam irradiated at $150 \mathrm{kGy}$. The grafting reaction was then carried out in an emulsion containing $3 \mathrm{wt} \%$ of 4-chloromethyl styrene (CMS) for $24 \mathrm{~h}$ at $30{ }^{\circ} \mathrm{C}$. After washing, the grafting rate was calculated gravimetrically.

\footnotetext{
* Corresponding authors.

E-mail addresses: roland_hag@ul.edu.lb (R. El Hage), rodolphe.sonnier@mines-ales.fr (R. Sonnier).
} 


$$
\text { vinylphosphonic acid }
$$

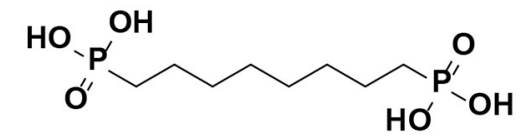

octane-1,8-diylbis(phosphonic acid)

(C8)<smiles>O=P(O)(O)CCCCCCCP(=O)(O)O</smiles>

hexane-1,6-diylbis(phosphonic acid)

(C6)<smiles>O=P(O)(O)CCCCCCCCCCCP(=O)(O)O</smiles>

decane-1,10-diylbis(phosphonic acid)

(C10)

Fig. 1. Flame retardants used in this study.

The absence of grafting was noted when non-delignified kenaf fibers were used, suggesting that the presence of lignin inhibits copolymerization. Inhibition by lignin appears to be due to the trapping of growing polymer radicals in the lignin network and thus limits the spread of polymerization. From a lignin content of less than $4 \mathrm{wt} \%$, the CMS begins to graft onto the partially delignified kenaf. The increase in the degree of grafting with the elimination of lignin can be also assigned to the additional accessibility of the crystalline regions of cellulose. When kenaf was partially delignified with $1.03 \mathrm{wt} \%$ residual lignin, the grafting rate was maximal, about $134 \%$.

Previously, Dorez et al. [28] modified flax fibers in mild chemical conditions through a condensation reaction of octadecylphosphonic acid (ODPA) with hydroxyl functions of these vegetal fibers. Flax fibers were modified by ODPA under ethanol reflux with stirring during $5 \mathrm{~h}$. Cellulose, xylan (used as model compound for hemicellulose) and lignin were also treated separately through the same procedure and under the same conditions. Only $5 \mathrm{wt} \%$ of ODPA was grafted onto flax fibers corresponding to $0.5 \mathrm{wt} \%$ of phosphorus content. The authors assumed that ODPA was reacted mainly with phenols from lignin.

We previously reported [20] the comparison between chemical modification by condensation and radiation grafting of vinyl phosphonic acid (VPA) on flax fabrics. In chemical modification by condensation reaction, fabrics were treated in different solutions containing VPA at a temperature range from $70{ }^{\circ} \mathrm{C}$ to $160^{\circ} \mathrm{C}$. In radiation grafting, fabrics were dipped in a solution containing VPA then irradiated at different doses under e-beam radiation (mutual grafting), and finally washed with water in order to remove the ungrafted molecules and macromolecules. Chemical modification in mild conditions (condensation only with phenol groups) was not highlighted as an efficient method to graft phosphorus on flax fabrics because flax contains only $3 \mathrm{wt} \%$ of lignin. In severe conditions which allow also condensation with hydroxyl groups of cellulose (81 wt $\%$ of flax composition), high amount of phosphorus was grafted (2.31 wt\%). However, such treatment at high temperature was very degradant for flax fabrics. Radiation grafting was more successful as a grafting route of VPA when sufficient amount of grafted phosphorus $(1.4 \mathrm{wt} \%)$ is able to improve the flame retardancy without degrading the fabrics. Note that using this procedure, VPA is covalently grafted or only trapped into the fiber structure after homopolymerization. Moreover, the penetration of FR into the bulk of the natural fiber (and then the final content of phosphorus) can be easily controlled by the proper choice of solvent. For example, we already [21] showed that using water instead of THF allowed the dimethyl(methacryloyloxy)methyl phosphonate (MAPC1) to penetrate to the bulk of the flax fiber. As a conclusion, radiation grafting method was considered as more suitable to natural fibers that contains low lignin content.

Miscanthus $x$ giganteus $(\mathrm{MxG})$ is the result of hybridization between Miscanthus sinensis and Miscanthus sacchariflorus. It is getting more attention and so more cultivated in Europe among the last decade [31]. It can be cultivated in more various climatic zones than other crops like hemp and flax [32]. Those fibers have been explored for biofuel production and adhesive fabrication [33-40]. Recently, they have been also used for the preparation of thermal isolating biocomposites [41]. To the best of our knowledge, miscanthus fibers have never been modified with phosphorus flame retardants. Thus, the aim of this work is to study the effect of the composition of two natural fibers (flax and miscanthus) on phosphorus grafting through two modification ways in order to impart flame retardancy. Moreover, based on literature, the flame retardancy seemed to be independent of the flame retardant structure and its thermal stability but rather related to the phosphorus content only $[21,22]$. This work reflects the importance of the relation between the thermal stability of the flame retardant and the fibers.

\section{Experimental}

\subsection{Materials}

Flax fabric was supplied by Hexcel (France). The weight of the fabric was $200 \mathrm{~g} / \mathrm{m}^{2}$. Flax fabrics are composed of $81 \mathrm{wt} \%$ of cellulose, $13 \mathrm{wt} \%$ of hemicelluloses, and $2.7 \mathrm{wt} \%$ of lignin. Miscanthus fibers were supplied by FRD company (Troyes, France) and are mainly composed of $59 \mathrm{wt} \%$ of cellulose, $21 \mathrm{wt} \%$ of hemicelluloses, and $20 \mathrm{wt} \%$ of lignin.

The miscanthus fibers were ground in a non-standardized mill to a fiber length of $630 \mu \mathrm{m}$. Extractives-free fibers were obtained after washing $10 \mathrm{~g}$ of fibers in a Soxhlet extractor for $6 \mathrm{~h}$ using toluene/ ethanol mixture with a volume ratio of $2 / 1$ and absolute ethanol for $16 \mathrm{~h}[42,43]$. Finally, the free-extractive fibers were dried in an oven at $60{ }^{\circ} \mathrm{C}$ for $5 \mathrm{~h}$. The extractive contents were measured by weighting miscanthus fibers before and after the extraction process, and by measuring the mass of the extractives after removing the solvent and drying. The extractive contents are around $5 \mathrm{wt} \%$.

C6, C8, C10 bisphosphonic acids (Fig. 1, Table 1) were supplied by "Specific Polymers" (Castries, France). Vinyl phosphonic avid (VPA) was supplied by ABCR-Gmbh (Karlsruhe, Germany).

Table 1

Phosphorus content of the different flame retardants used in this work.

\begin{tabular}{ll}
\hline Molecule & Phosphorus content (wt\%) \\
\hline VPA & 28.7 \\
C6 & 25.2 \\
C8 & 22.6 \\
C10 & 20.5 \\
\hline
\end{tabular}




\subsection{Miscanthus fibers modification by mutual radiation grafting}

The process of modifying miscanthus fibers by mutual radiation grafting was similar to that followed for flax previously [20-23]. About $2 \mathrm{~g}$ of raw and extractives-free miscanthus fibers were impregnated for $1 \mathrm{~min}$ in a VPA aqueous solution. A fiber/solution mass ratio of $1 / 10$ was used. The VPA aqueous solution concentration was adjusted to reach $1 \mathrm{wt} \%, 5 \mathrm{wt} \%$ and $10 \mathrm{wt} \%$. After impregnation, the fibers were placed in a hood for $24 \mathrm{~h}$ at room temperature to achieve fibers drying. These fibers were i rradiated for few s econds under a ir a nd at room temperature by e-beam radiation at $50 \mathrm{kGy}$ (energy $9.8 \mathrm{MeV}$, power $27 \mathrm{~kW}$ ) at Ionisos SA (Chaumesnil, France). The irradiated fibers were washed three times at room temperature with demineralized water. Each washing was carried out under magnetic agitation for one minute to remove the ungrafted monomers, oligomers or polymers. The fibers were dried in a hood for $48 \mathrm{~h}$ at room temperature before analysis.

\subsection{Flax fabrics and miscanthus fibers chemical modification}

Approximately $0.25 \mathrm{~g}$ of flax fabric $\left(5 \times 3 \mathrm{~cm}^{2}\right)$ or extractives-free miscanthus fibers were mixed in a $50 \mathrm{ml}$ round bottom flask with $20 \mathrm{~g}$ of ethanol/water mixture (90/10 wt $\% / w t \%)$ containing $5 \mathrm{wt} \%$ or $10 \mathrm{wt}$ $\%$ of the bisphosphonic acid molecule or VPA. The mixture was heated under reflux at $80^{\circ} \mathrm{C}$. Based on preliminary tests, the process time was optimized at $2 \mathrm{~h}$. At the end of each treatment, the liquid phase was filtered. The treated flax fabrics and miscanthus fibers were then washed three times for one minute with ethanol and dried at room temperature to remove the ungrafted molecules.

\subsection{Characterizations}

\subsubsection{X-ray fluorescence elemental analysis}

Phosphorus content in flax fabrics was determined using an Oxford XMET 5100 X-ray fluorescence. Samples were fixed on a flat polymerbased support containing no trace of phosphorus. This holder is used to flatten tissues to reduce instrumental errors. The analyses were carried out under atmospheric pressure, without any preparation. The following settings were used by default: $13 \mathrm{kV}$ and $45 \mu \mathrm{A}$. Each spectrum was collected for $1 \mathrm{~min}$. As the intensity of the phosphorus peak is proportional to its concentration, data were collected and converted by a simple calculation to determine the mass percentage of phosphorus. This instrument was previously calibrated using samples of known phosphorus concentration measured by inductively coupled plasma spectrometry (ICP-AES). Thus, a calibration curve was plotted [20,21]. The mean values of phosphorus content were calculated based on 3 times collected measurements for each sample.

\subsubsection{Inductively coupled plasma spectrometry (ICP-AES)}

Inductively coupled plasma spectrometry (ICP-AES) is a destructive technique used to determine the elemental composition of a material. Samples undergo a preliminary step of mineralization before analysis. About $50 \mathrm{mg}$ of flax or miscanthus fibers were mixed with $1 \mathrm{ml}$ of nitric acid $(63 \%)$ and $2 \mathrm{ml}$ of sulphuric acid $(98 \%)$ in a Teflon container. The mixture was heated by microwaves with powers between 400 and $700 \mathrm{~W}$ in an appropriate cycle. After cooling, the mineralized solutions were diluted with demineralized water to $50 \mathrm{ml}$ before being analyzed by ICP-AES. During this step, the vaporized solution passes through the plasma chamber at $6000{ }^{\circ} \mathrm{C}$ and the excited atoms emit spectra specific to each element. The peak intensity of the phosphorus element is converted to a mass percentage based on a calibration curve. Each sample was analyzed 3 times to ensure reproducibility of the measurements.

\subsubsection{Scanning electron microscopy (SEM)}

Fiber micrographs were obtained using a scanning electron microscope (FE I Quanta 200). The fibers w ere o bserved u sing a vertical sample holder under high vacuum at a voltage of $12.5 \mathrm{kV}$ and a working distance of $10 \mathrm{~mm}$. Phosphorus was located in the miscanthus and flax fibers using an energy dispersive X-ray spectroscopy, EDX, (Oxford INCA Energy system).

\subsubsection{Thermogravimetric analysis (TGA)}

A Setaram Setsys apparatus was used to perform thermogravimetric analysis. Around $10 \mathrm{mg}$ of each sample $( \pm 1 \mathrm{mg}$ ) were heated in alumina ceramic crucibles from 30 to $800{ }^{\circ} \mathrm{C}$ at a heating rate of $10{ }^{\circ} \mathrm{C} / \mathrm{min}$ under nitrogen atmosphere $(100 \mathrm{ml} / \mathrm{min})$. Residual weight at $750{ }^{\circ} \mathrm{C}$ $\left(\operatorname{Res}_{750}\right)$ was determined.

\subsubsection{Pyrolysis combustion flow calorimetry (PCFC)}

Fire behavior of samples at microscale was investigated using a pyrolysis combustion flow calorimeter (Fire Testing Technology Ltd., UK). Sample (2-4 mg) pyrolysis was performed at a heating rate of $1{ }^{\circ} \mathrm{C} / \mathrm{s}$ under a nitrogen flow $\left(100 \mathrm{ml} / \mathrm{min}\right.$ ) from 90 to $750{ }^{\circ} \mathrm{C}$ (anaerobic pyrolysis - method A according to the standard ASTM D7309). Pyrolysis gases were carried to a combustor in the presence of a $\mathrm{N}_{2} / \mathrm{O}_{2}$ $(80 / 20)$ mixture. All gases are fully oxidized in such conditions. Heat Rate Release (HRR) was calculated according to Huggett's relation [44] which states that $1 \mathrm{~kg}$ of consumed oxygen corresponds to $13.1 \mathrm{MJ}$ of heat release. Each test was performed twice to ensure the reproducibility of the measurements. The peak of heat rate release (pHRR), the temperature at $\mathrm{pHRR}\left(\mathrm{T}_{\max }\right)$, the total heat release (THR) were determined.

\section{Results and discussion}

\subsection{Evaluation of phosphorus radiation grafting on $M x G$ fibers and flax fabrics}

Raw and extractive-free MxG fibers were impregnated in aqueous VPA solutions with different concentrations and then dried and irradiated at $50 \mathrm{kGy}$. The treated fibers were washed with water and dried. The phosphorus content was determined by ICP-AES (Fig. 2). For a concentration of $5 \mathrm{wt} \%$ of VPA in the impregnation solution, the resulting fibers contain $0.88 \mathrm{wt} \%$ of phosphorus ( $3.1 \mathrm{wt} \%$ of VPA) for raw fibers, and $0.81 \mathrm{wt} \%$ phosphorus ( $2.8 \mathrm{wt} \%$ of VPA) for extractive-free fibers. The slight difference in the phosphorus content between the two fibers is not significant. Higher concentration of VPA (10 wt $\%)$ leads to higher phosphorus contents. It reached a value of $1.35 \mathrm{wt} \%$ ( $4.7 \mathrm{wt} \%$ of VPA) for raw miscanthus fibers and $1.68 \mathrm{wt} \%$ (5.9 wt $\%$ of VPA) for extractive-free fibers. The difference in phosphorus contents in this case is not negligible. Two hypotheses may be proposed for this observation. According to the literature [45], aromatic compounds play a protective role in the radiolysis of cellulose. Thus, the first hypothesis suggests that the presence of aromatic compounds in extractives may limit the cleavage of cellulose chains. As a result, fewer reactive free radicals are formed on the components of miscanthus in the presence of extractives (raw miscanthus fibers), which leads to lower grafting rates.

The second hypothesis assumes that the extractives may limit the available reactive sites of cellulose that allow reaction with VPA. In fact, VPA accessibility to cellulose may be limited during impregnation step. Thus, the VPA is grafted in smaller quantities onto the cellulose. VPA grafting is more sensitive to these phenomena when the concentration of the molecule is high (10 wt $\%$ of VPA in impregnation solution) than at lower concentrations.

As polyphenols, lignin should prevent the radiation-grafting. We showed in previous studies that for concentrations of $5 \mathrm{wt} \%$ and $10 \mathrm{wt}$ $\%$ of VPA and an irradiation dose of $50 \mathrm{kGy}$, the phosphorus contents grafted onto flax fabrics reached $1.10 \mathrm{wt} \%$ and $1.38 \mathrm{wt} \%$ respectively [20,21]. The phosphorus contents are therefore of the same order for flax and miscanthus (Fig. 2). Even if phosphorus contents cannot be precisely compared between the two fibers because the measurement technique is not identical, it is clear that lignin does not seem to be detrimental for radiation-grafting in this work. This is in apparent 


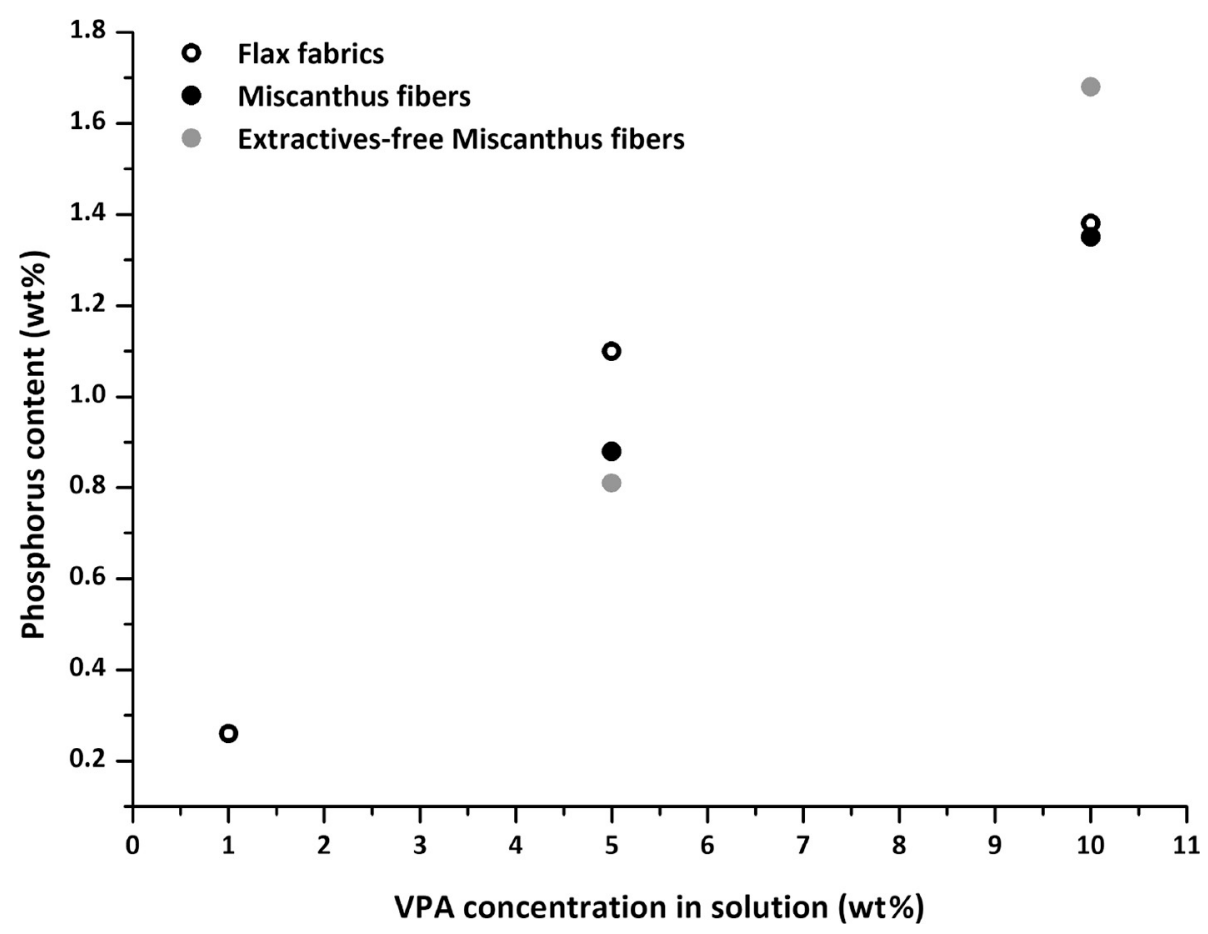

Fig. 2. Phosphorus content of flax fabrics and miscanthus fibers modified by radiation grafting (phosphorus contents for flax fabrics are extracted from previous studies $[20,21])$

contradiction with literature, and especially works of Sharif et al. [29] and Mohamed et al. [30]. Nevertheless, these authors carried out preirradiation method while the mutual radiation grafting was chosen in the present work. Moreover, remind that VPA can be only trapped into natural fibers structure after homopolymerization upon radiation [21]. In this case, the presence of lignin as radical inhibitor is probably meaningless.

\subsection{Evaluation of phosphorus chemical grafting on $M x G$ fibers and flax fabrics}

Extractive-free MxG fibers and flax fabrics were treated under mild conditions $\left(80{ }^{\circ} \mathrm{C}\right)$ in an ethanol/water mixture $(90 / 10)$ for $2 \mathrm{~h}$ with different concentrations of $\mathrm{C} 6, \mathrm{C} 8$ and $\mathrm{C} 10$ bisphosphonic acids and VPA as described in the experimental part.

Fig. 3 shows the final phosphorus content measured by ICP-AES of flax fabrics and MxG fibers treated with bisphosphonic acids and VPA by chemical modification under mild conditions.

As observed in Fig. 3, phosphorus contents grafted onto flax fabric under mild conditions are very low $(<0.3 \mathrm{wt} \%)$. However, the phosphorus contents grafted on miscanthus are much higher than those grafted on flax under the same conditions. Using a solution containing $5 \mathrm{wt} \%$ of $\mathrm{C} 6$ bisphosphonic acid, the grafted phosphorus content for miscanthus reaches a value of $1.4 \mathrm{wt} \%$ compared to $0.3 \mathrm{wt} \%$ for flax (5.6 wt $\%$ versus $1.2 \mathrm{wt} \%$ of C6). C8 and C10 bisphosphonic acids graft onto miscanthus fibers with a phosphorus content of about $0.9 \mathrm{wt} \%$ (3.9 wt $\%$ of C8 and $4.4 \mathrm{wt} \%$ of C10). This confirms the role of the chemical composition of the natural fiber. As said previously, phosphonic functions have a preferential reactivity towards the phenol groups of lignin [28]. Miscanthus fibers are richer in lignin than flax fibers. Thus, bisphosphonic acids are better grafted onto miscanthus fibers. However, VPA grafting seems to be less effective than bisphosphonic acids. Phosphorus levels are low for both flax and miscanthus fibers. No clear explanation could be attributed to this phenomenon.

SEM - EDX observations were carried out to locate phosphorus within the miscanthus and flax fibers (Fig. 4). Miscanthus and flax fibers have different microscopic structures. Miscanthus fibers have a

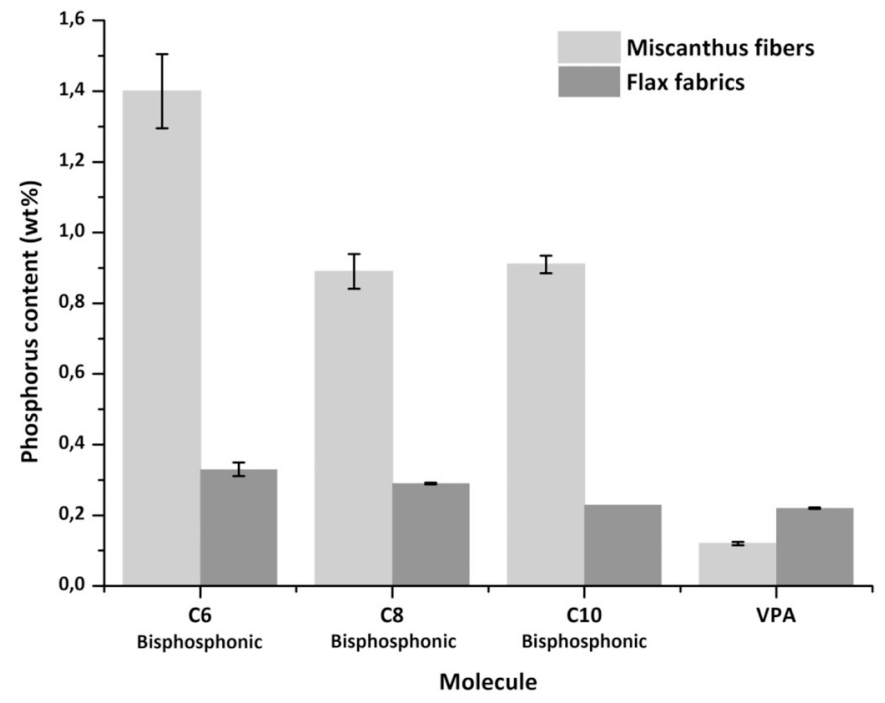

Fig. 3. Variation in the phosphorus content grafted on miscanthus fibers and flax fabrics by condensation reaction under mild conditions with $5 \mathrm{wt} \%$ of the bisphosphonic molecules in the reaction solution.

porous structure clearly observable by SEM. For flax elementary fibers no porosity is visible, only lumen (if any) is observed by SEM. Phosphorus mapping shows that FR penetrates into the core of flax and miscanthus fibers. Therefore, the difference in the grafted phosphorus content between flax and miscanthus may be not related to the degree of diffusion of the molecule within the fibers. This may indicate that the chemical composition of the two fibers (in particular the lignin content) is the main factor that determines the amount of final phosphorus in the fibers in the case of condensation reaction. 

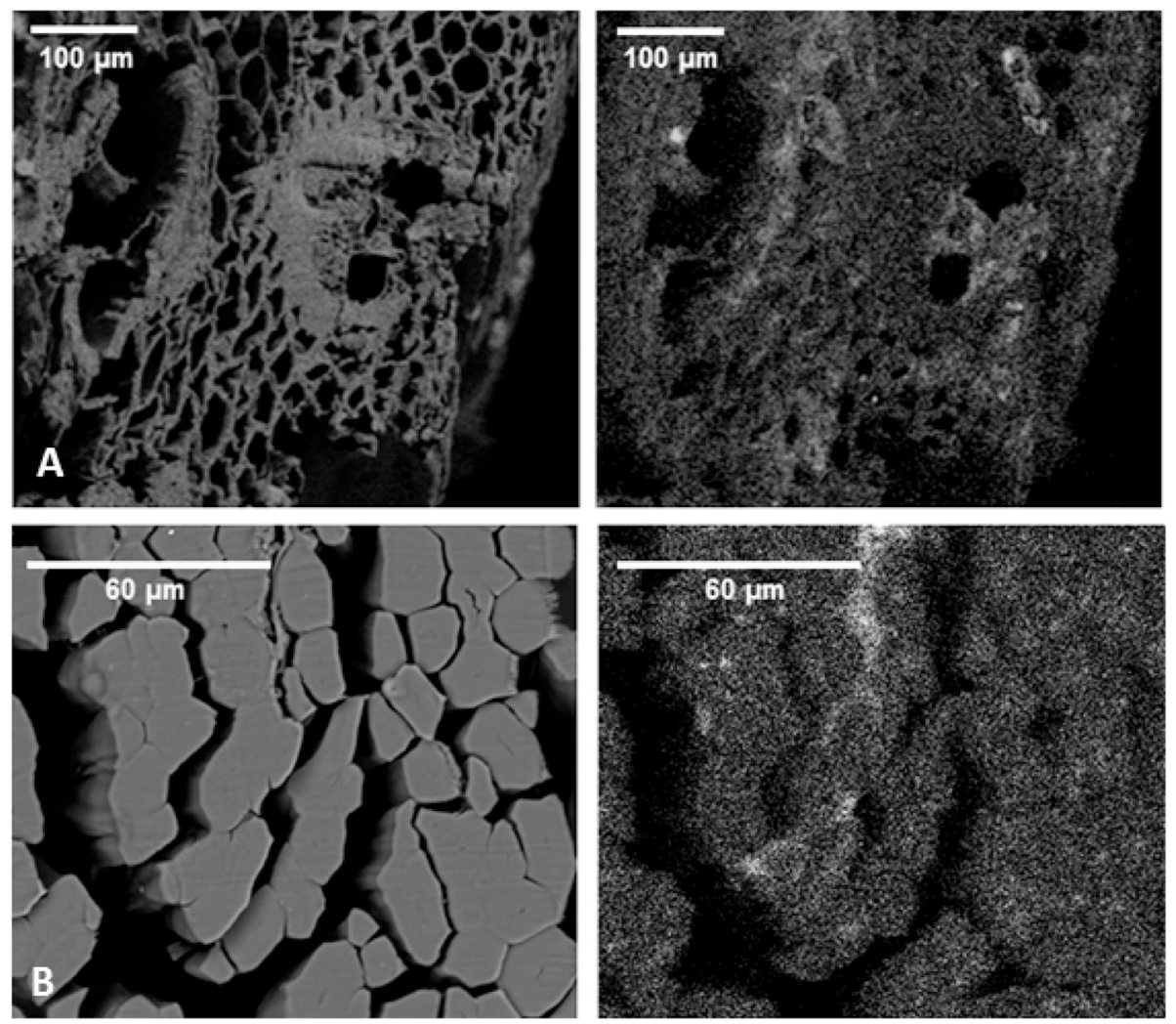

Fig. 4. SEM images (left) and EDX phosphorus mapping (right) of miscanthus fibers (A) and flax fibers (B) treated with solutions of 5 wt $\%$ C6 bisphosphonic acid aqueous solutions by chemical modification under mild conditions

\subsection{Effect of the phosphorus content on the thermal degradation of the fibers}

The effect of phosphorus content on miscanthus fibers was studied at microscale by thermogravimetric analysis and pyrolysis combustion flow calorimetry (anaerobic pyrolysis).. Fig. 5 shows the HRR (PCFC) curves for miscanthus fibers before and after removal of extractives. The anaerobic decomposition of miscanthus involves different steps corresponding to the main components of miscanthus (cellulose, hemicelluloses, and lignin). The HRR curve of the miscanthus shows a shoulder towards $305^{\circ} \mathrm{C}$ and a main peak towards $358^{\circ} \mathrm{C}$. From $400{ }^{\circ} \mathrm{C}$, the HRR curve slowly decreases, which may correspond to a third peak

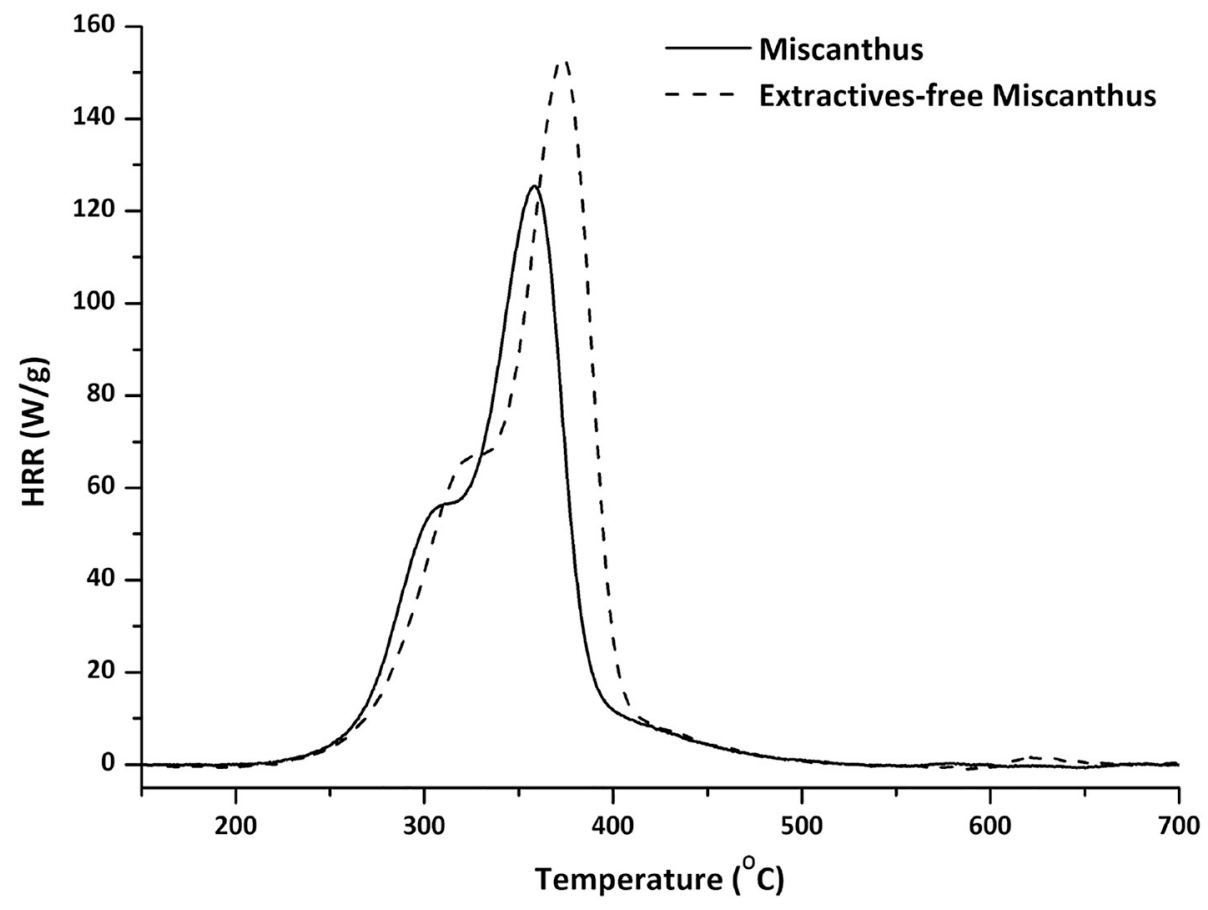

Fig. 5. HRR curves for miscanthus fibers before and after removal of extractives. 
that is hardly defined. After removal of extractives, the main peak increases to $375{ }^{\circ} \mathrm{C}$ with a shoulder at $320{ }^{\circ} \mathrm{C}$. In fact, extractives are noncellulosic components (oils, fats, waxes, etc.) which can degrade at temperatures between $110{ }^{\circ} \mathrm{C}$ and $270{ }^{\circ} \mathrm{C}$ [46]. Thus, the presence of extractives can cause fiber degradation at lower temperatures.

Dorez et al. [47] studied the anaerobic degradation of cellulose, xylan (e.g. hemicelluloses), and lignin. Cellulose is characterized by a pHRR of $141 \mathrm{~W} / \mathrm{g}$ at $370{ }^{\circ} \mathrm{C}$. Xylan has two less intense pHRRs than cellulose of $35 \mathrm{~W} / \mathrm{g}$ and $48 \mathrm{~W} / \mathrm{g}$ at $252{ }^{\circ} \mathrm{C}$ and $304{ }^{\circ} \mathrm{C}$ respectively. Lignin is characterized by slow degradation starting around $250{ }^{\circ} \mathrm{C}$ and ending around $400{ }^{\circ} \mathrm{C}$ with a pHRR of $36 \mathrm{~W} / \mathrm{g}$ at $350{ }^{\circ} \mathrm{C}$. Thus, the shoulder around $320{ }^{\circ} \mathrm{C}$ corresponds to the decomposition of hemicelluloses. The main peak around $375{ }^{\circ} \mathrm{C}$ corresponds to cellulose and there is a third hardly defined peak corresponding to lignin.

The flame propagation of a combustible material needs sufficient heat to be transferred from a heat source to the material. Thus, the material decomposes at a characteristic temperature, through an anaerobic mechanism (pyrolysis). In the pyrolysis of cellulose, there are two competitive reactions $[13,48]$ : the first is a dehydration reaction of the cellulose leading to the formation of char, and the other is a depolymerization reaction leading to the formation of levoglucosan $[12,13,48,49]$. The latter decomposes to form very low molecular weight species with very high flammability and also some char [13]. The vapors released must react with the oxidant (typically oxygen present in air) to maintain combustion and the flame propagation process [13,50]. Phosphorus flame $r$ etardants $\mathrm{c}$ an $\mathrm{r}$ eact in the condensed phase by releasing acidic molecules that catalyze the cellulose dehydration reaction and thus promote the formation of char rather than the levoglucosan formation reaction (Scheme 1) [13,51].

The radiation grafting of VPA on miscanthus fibers $(0.81 \mathrm{wt} \%$ phosphorus) increases the residue yield while accelerating the degradation process of miscanthus (Fig. 6). Those observations are discussed below. The first mass loss observed below $150{ }^{\circ} \mathrm{C}$ in TGA curves corresponds to moisture removal which cannot be observed in PCFC results (Fig. 7). Moreover, radiation grafting of VPA reduces the peak of mass loss rate (dTG) from 11.2 to $7.2 \% / \mathrm{min}$ (Fig. $6 \mathrm{~b}$ ) and the pHRR of miscanthus to $78 \mathrm{~W} / \mathrm{g}$ compared to $153 \mathrm{~W} / \mathrm{g}$ for the untreated fibers (Fig. 7). In addition, the shoulder that appears around $320^{\circ} \mathrm{C}$ in PCFC for the untreated miscanthus merges with the main peak after radiation grafting of VPA at $268{ }^{\circ} \mathrm{C}$. However, the shoulder still appears clearly with a lower intensity in TGA (because of the lower heating rate). The third peak, estimated at around $400{ }^{\circ} \mathrm{C}$ (Figs. $6 \mathrm{~b}$ and 7) and assigned to lignin decomposition, appears more clearly without any decrease in its intensity.

This third peak is more visible after modification of the miscanthus fibers with phosphorus flame retardants. Cellulose phosphorylation catalyzes its degradation during pyrolysis and decreases its maximum degradation temperature $[13,28,49,52,53]$ while lignin phosphorylation increases its thermal stability and increases its maximum degradation temperature (about $410{ }^{\circ} \mathrm{C}$ ) [28,53-56]. During anaerobic pyrolysis, the peaks of unmodified cellulose and lignin overlap. But, after the phosphorylation of miscanthus fibers, the maximum degradation temperature of cellulose decreases while that of lignin increases, allowing the separation of these two peaks.

Those results indicate that the VPA may be mainly grafted onto cellulose and hemicelluloses. These analyses would have to be confirmed by radiation grafting experiments on the pure components of miscanthus (cellulose, hemicelluloses and lignin).

The radiation grafting of VPA on flax fibers $(1.10 \mathrm{wt} \%$ of phosphorus) reduces the pHRR of flax fibers from $208 \mathrm{~W} / \mathrm{g}$ to $60 \mathrm{~W} / \mathrm{g}$. The temperature at pHRR shifted from $364{ }^{\circ} \mathrm{C}$ to $272{ }^{\circ} \mathrm{C}$ without any appearance of new peaks. In fact, the amount of lignin in flax fibers is too low (around 3\%) to be detected during pyrolysis.

From the comparison between flax and miscanthus, we can suggest that radiation grafting on flax fibers is more efficient due their higher amount of cellulose and hemicellulose $(97 \%$ for flax vs $80 \%$ for miscanthus). The phosphorus amounts compared grafted on both fibers are almost the same. However, the pHRR of flax was reduced by $71 \%$ when the pHRR of miscanthus was reduced only by $49 \%$ while the temperature at pHRR is identical for both modified fibers.

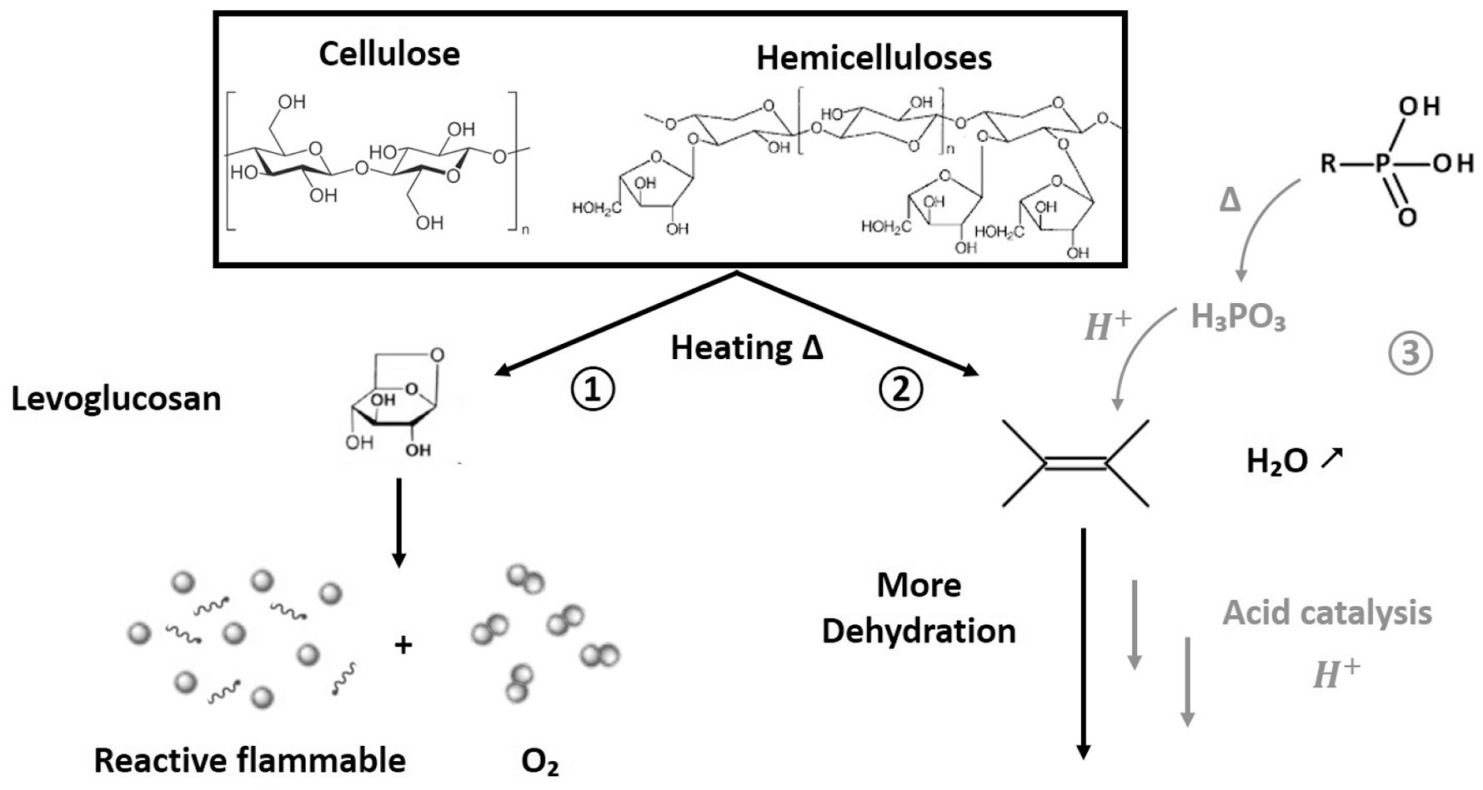

species

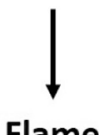

Char formation

Flame

Lower flammability

Scheme 1. Mechanism of degradation of cellulosic material by 1) depolymerization, 2) dehydration and 3) promotion of mechanism 2 in presence of phosphonic flame retardant. 

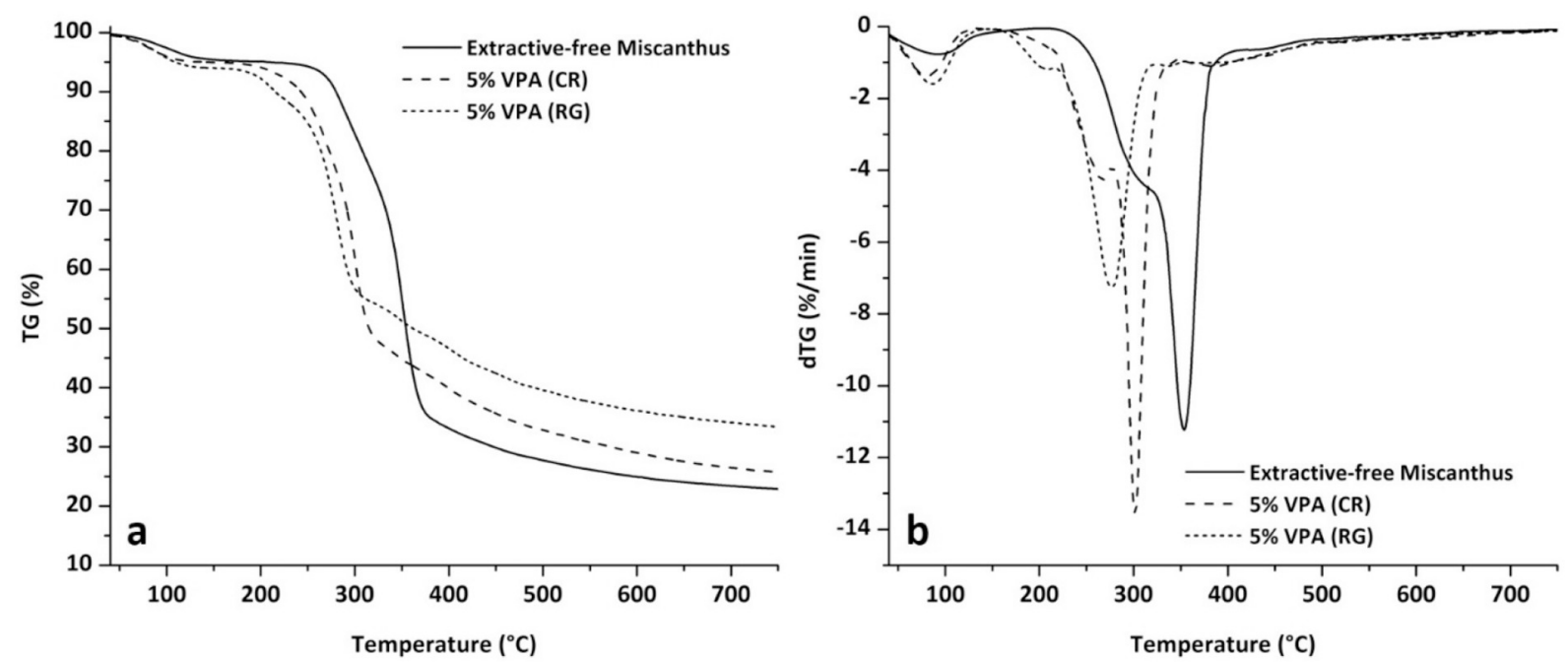

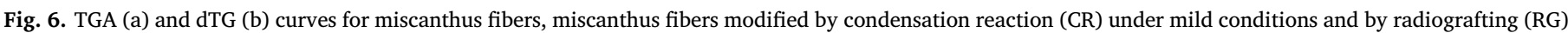
at $50 \mathrm{kGy}$ with a $5 \mathrm{wt} \%$ VPA solution.

The modification of miscanthus fibers by $10 \mathrm{wt} \%$ of VPA or C6, C8 and $\mathrm{C} 10$ bisphosphonic acids, by condensation reaction under mild conditions, is compared by PCFC and TGA (Figs. 8 and 9).

The modification of miscanthus fibers by VPA $(0.59 \mathrm{wt} \%$ phosphorus) shows a decrease in pHRR from $153 \mathrm{~W} / \mathrm{g}$ to $136 \mathrm{~W} / \mathrm{g}$ with a decrease in maximum degradation temperature from $375{ }^{\circ} \mathrm{C}$ to $297{ }^{\circ} \mathrm{C}$ compared to unmodified miscanthus. Similar behavior was observed in TGA where the peak of mass loss rate (dTG) decreased from 11.2 to $8.1 \% / \mathrm{min}$ with the same temperature changes. Moreover, the shoulder corresponding to hemicelluloses merges with the main peak of cellulose whereas the third peak corresponding to lignin appears around $400{ }^{\circ} \mathrm{C}$ in both techniques.

The grafting of bisphosphonic acids under mild conditions allows higher phosphorus contents to be obtained on the miscanthus fibers in comparison to flax. The so-modified fibers were compared to extractives-free miscanthus. In fact, preliminary tests showed a removal of extractives by ethanol from raw miscanthus fibers during the chemical modification process. The HRR and dTG curves of the modified fibers show an overlap of the peaks corresponding to hemicelluloses and cellulose with a clearer appearance of the peak corresponding to lignin around $400{ }^{\circ} \mathrm{C}$. We can observe that when phosphorus content increases, the pHRR value decreases. The pHRR of the modified miscanthus reaches values of $109 \mathrm{~W} / \mathrm{g}, 102 \mathrm{~W} / \mathrm{g}$ and $85 \mathrm{~W} / \mathrm{g}$ using $10 \mathrm{wt} \%$ of C10, C8 and C6 bisphosphonic acids respectively. The presence of the bisphosphonic acids flame retardants reduces the maximum degradation temperature, but it seems to be slightly influenced by the phosphorus content. Miscanthus fibers modified by $\mathrm{C} 10$ bisphosphonic acid (1.13 wt $\%$ of phosphorus) degrade at $316{ }^{\circ} \mathrm{C}$ while fibers modified by C6 and C8 bisphosphonic acids (2.12 wt \% and $1.63 \mathrm{wt} \%$ phosphorus respectively) degrade at $304{ }^{\circ} \mathrm{C}$. Residues yield at $750{ }^{\circ} \mathrm{C}$ is about $38 \%$ for fibers modified with bisphosphonic acids while it is around $34 \%$ for fibers modified with VPA. Degradation temperatures and char yields are only slightly higher for fibers modified by bisphosphonic acids than those modified by the VPA under the same conditions, despite much

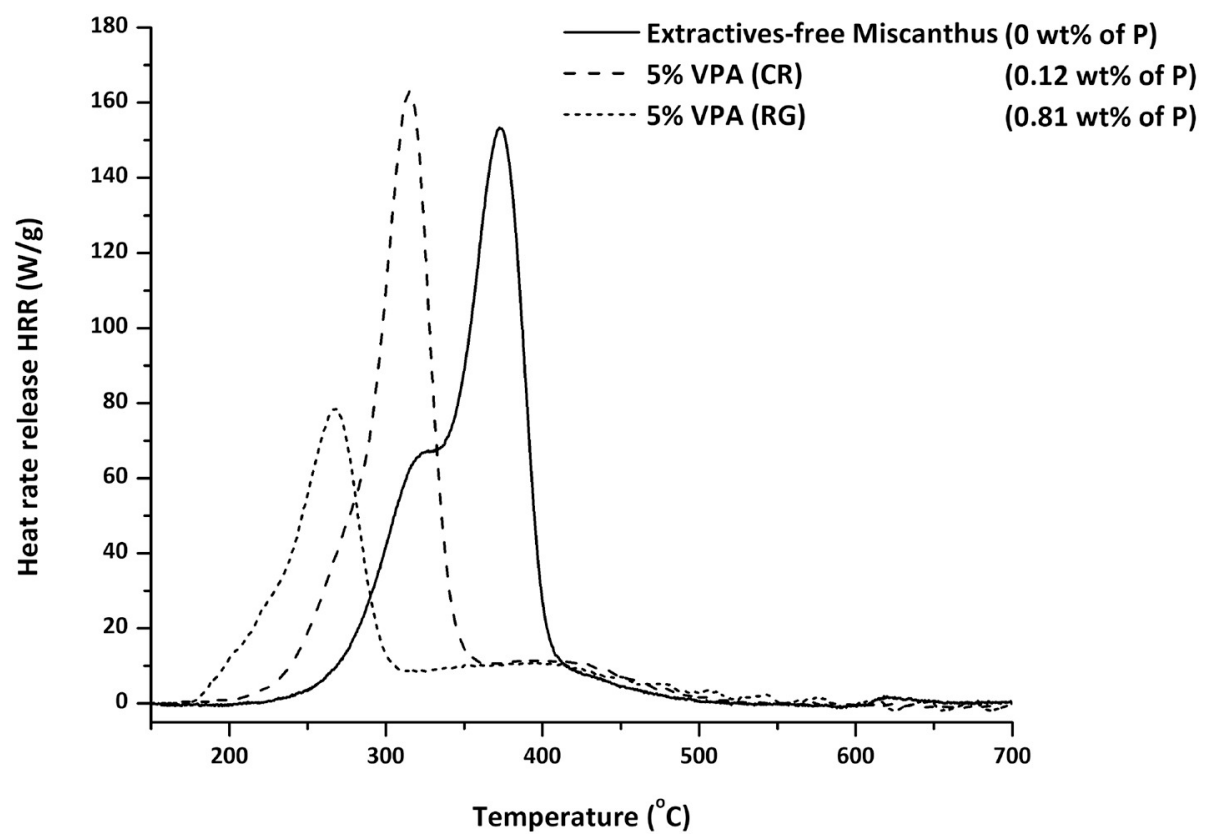

Fig. 7. HRR curves for miscanthus fibers, miscanthus fibers modified by condensation reaction (CR) under mild conditions and by radiografting (RG) at $50 \mathrm{kGy}$ with a $5 \mathrm{wt} \%$ VPA solution. 


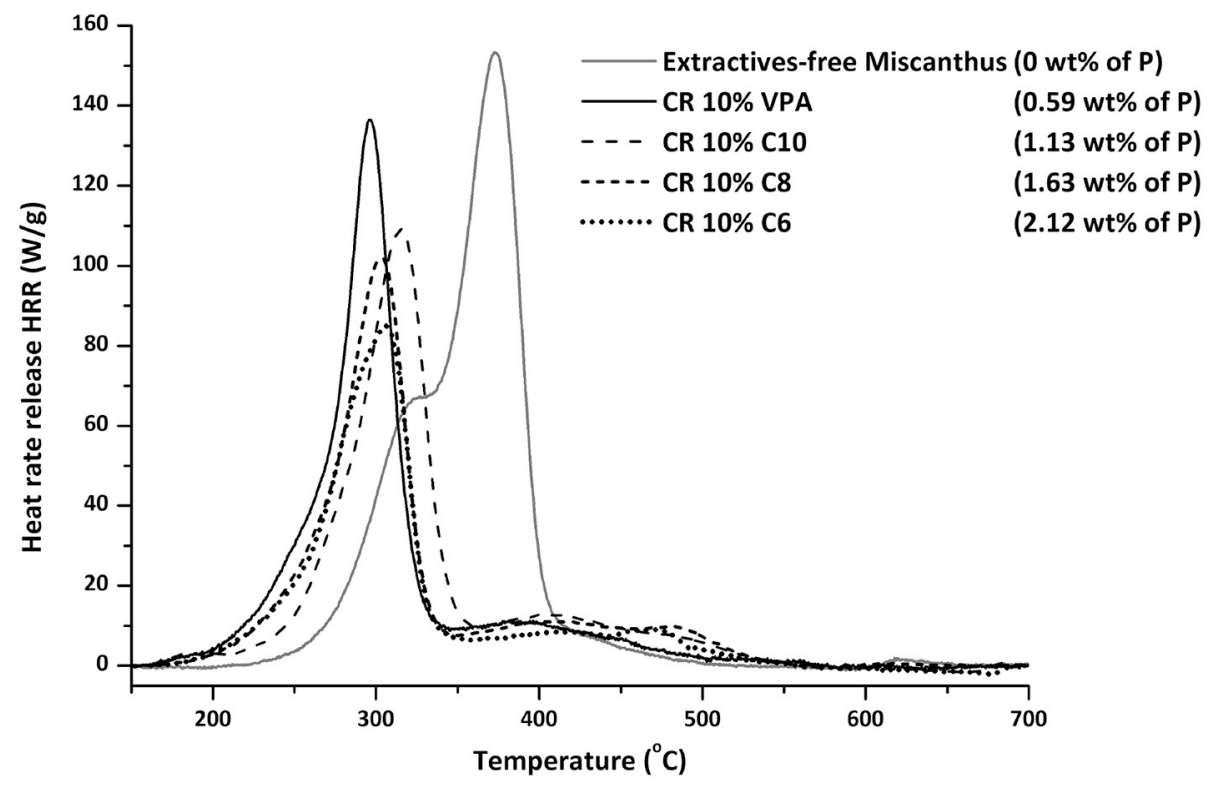

Fig. 8. HRR curves for miscanthus fibers and for miscanthus fibers modified by condensation reaction (CR) under mild conditions with a 10 wt $\%$ solution of VPA, C10, C8 or C6.
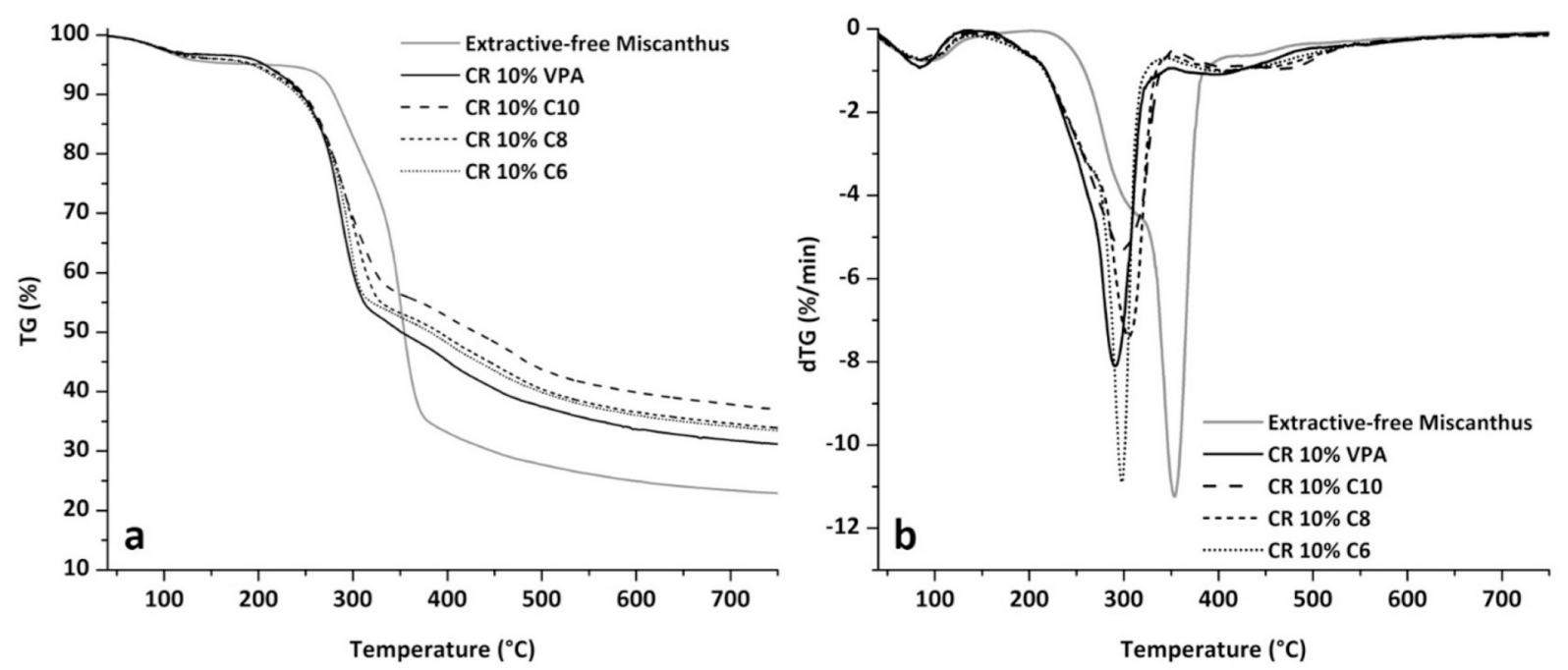

Fig. 9. TGA (a) and dTG (b) curves for miscanthus fibers and for miscanthus fibers modified by condensation reaction (CR) under mild conditions with a 10 wt $\%$ solution of VPA, C10, C8 or C6.

higher phosphorus content with the formers. These points will be detailed later. The peak corresponding to the degradation of lignin also appears at $400{ }^{\circ} \mathrm{C}$ for all phosphorus concentrations grafted on miscanthus fibers by bisphosphonic acids with a pHRR of about $11 \mathrm{~W} / \mathrm{g}$. However, a fourth slight peak appears in PCFC and dTG between 450 and $500{ }^{\circ} \mathrm{C}$ after modification of miscanthus fibers by bisphosphonic acids. This peak corresponds to the decomposition of the grafted flame retardants used for fiber modifications.

Flax fabrics were also chemically modified by VPA and bisphosphonic acids under the same conditions as miscanthus fibers. Phosphorus contents of the different modified fabrics are so close between 0.22 and $0.33 \mathrm{wt} \%$. However, VPA seems to be a little bit more effective as flame retardant on flax fibers than bisphosphonic acids (Figs. 10 and 11). Maximal degradation temperature decreases from $364{ }^{\circ} \mathrm{C}$ to $310{ }^{\circ} \mathrm{C}$ after the chemical modification with $5 \mathrm{wt} \%$ of VPA while it decreases to around $343{ }^{\circ} \mathrm{C}$ with the different bisphosphonic acids. Also, pHRR and peak of dTG increase when flax fabrics are modified chemically with bisphosphonic acids while they decrease when flax is modified by VPA. In fact, we reported previously that the chemical modification process has an impact by itself on flax thermal degradation and thus it increases the pHRR values [20]. Also, a slight increase of THR values was observed when flax fabrics were modified by bisphosphonic acids from $9.1 \mathrm{~kJ} / \mathrm{mol}$ for unmodified flax fibers to $10.5 \mathrm{~kJ} / \mathrm{mol}$ for $\mathrm{C} 10$ modified fibers. In parallel, char yield slightly increased (Fig. 11a). This means that the presence of bisphosphonic acid at these low phosphorus contents does not improve the flame retardancy of flax.

Therefore, for VPA grafting, the pHRR and the maximum degradation temperature depend mainly on the level of phosphorus grafted onto the miscanthus fibers, regardless of the modification process. When the phosphorus level increases, the pHRR and the maximum degradation temperature decrease. This indicates that the presence of VPA in miscanthus fibers change the degradation path and limits the release of flammable species during fibers degradation. However, the presence of VPA destabilizes the fibers and thus, their degradation starts at lower temperatures than that of unmodified fibers. In fact, 


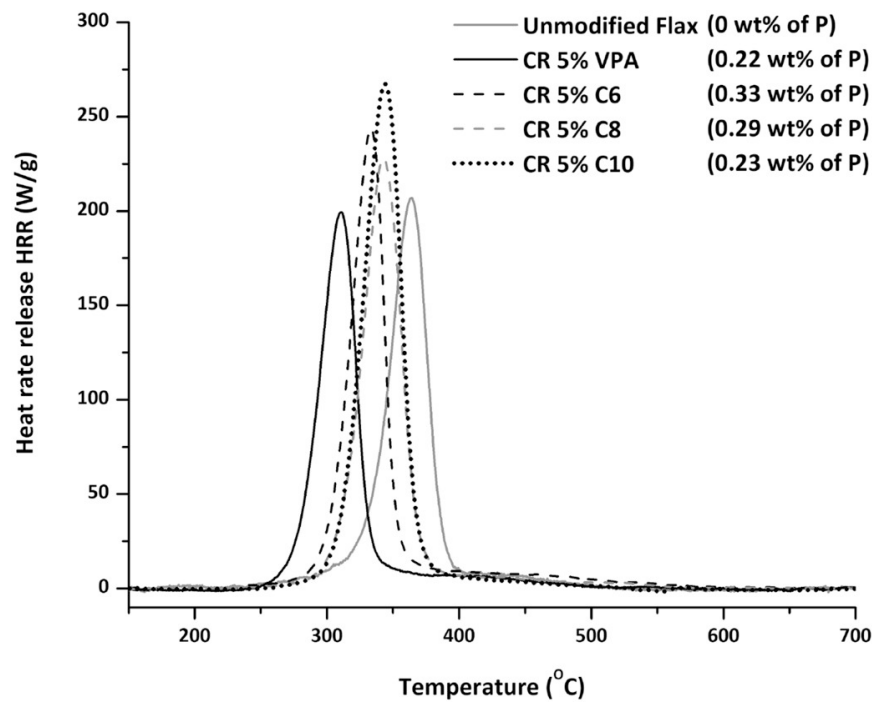

Fig. 10. HRR curves for unmodified flax fibers and for flax fibers modified by condensation reaction (CR) under mild conditions with a $5 \mathrm{wt} \%$ solution of VPA, C6, C8 or C10.

phosphonate groups degrade to release phosphonic acid [57] which thermally catalyzes the degradation of cellulose $[10,11]$. In the presence of acid, cellulose dehydration is promoted (release of water vapor) [13] and thus, fewer flammable species are released.

Previously [20-23], performance trends measured by PCFC and TGA were correlated only to the content of phosphorus grafted on flax fibers. Here, secondary but not negligible differences are observed depending on whether the grafting agent is VPA or bisphosphonic acid. As explained below, this may be related to the thermal stability of the flame retardants.

The anaerobic decomposition of flame retardants was analyzed by PCFC (Fig. 12). The thermal decomposition of VPA begins at $262{ }^{\circ} \mathrm{C}$ with a pHRR of $102 \mathrm{~W} / \mathrm{g}$ at a temperature of $327^{\circ} \mathrm{C}$ (slightly lower than those of the miscanthus and flax fibers which are around $358{ }^{\circ} \mathrm{C}$ and $363^{\circ} \mathrm{C}$ respectively). It is remarkable that the decomposition of the VPA occurs almost simultaneously with that of the miscanthus and flax fibers. Thermal decomposition of bisphosphonic acids begins around $392{ }^{\circ} \mathrm{C}, 418{ }^{\circ} \mathrm{C}$ and $453{ }^{\circ} \mathrm{C}$ for $\mathrm{C} 6, \mathrm{C} 10$ and C8 respectively. At such temperatures, the decomposition of flax and miscanthus is already almost completed. In addition, the maximum degradation temperatures of bisphosphonic acids are $448^{\circ} \mathrm{C}, 497^{\circ} \mathrm{C}$ and $474^{\circ} \mathrm{C}$ for $\mathrm{C} 6, \mathrm{C} 10$ and $\mathrm{C} 8$ respectively. This may explain the phenomena observed in PCFC after modification of miscanthus fibers with these molecules. In fact, bisphosphonic acids are more thermally stable compared to miscanthus, unlike VPA. These FR molecules do not decompose at the right time during the thermal degradation of miscanthus. As a result, the presence of phosphorus grafted from bisphosphonic FRs does not have the same effect as that of VPA on the thermal destabilization of fibers. Thus, with relatively high amounts of phosphorus in miscanthus fibers (between $1.13 \mathrm{wt} \%$ and $2.12 \mathrm{wt} \%$ ) the maximum degradation temperature does not vary significantly (between $304{ }^{\circ} \mathrm{C}$ and $316{ }^{\circ} \mathrm{C}$ ). Similarly, the pHRR values of bisphosphonic acids are $240 \mathrm{~W} / \mathrm{g}, 551 \mathrm{~W} / \mathrm{g}$ and $462 \mathrm{~W} / \mathrm{g}$ for C6, C10 and C8 respectively. These pHRR values are relatively high, which allows observing a shoulder at high temperature (between 400 and $500{ }^{\circ} \mathrm{C}$ ) during the anaerobic decomposition of miscanthus modified by these molecules, corresponding to the contribution of bisphosphonic acid degradation. This is especially observed when the quantity of these molecules in the fibers is high (between 5.5 and $8.3 \mathrm{wt} \%$ ).

The pHRR temperatures (obtained by PCFC) for the different treatments carried out on the miscanthus fibers are represented as a function of the corresponding phosphorus content (Fig. 13). It is clear that the degradation temperatures of VPA modified miscanthus fibers are lower than those of bisphosphonic acid modified fibers at similar phosphorus contents. The degradation temperatures of bisphosphonic acid modified miscanthus fibers range from 293 to $316^{\circ} \mathrm{C}$ while those of VPA modified fibers range from 270 to $311^{\circ} \mathrm{C}$. As previously stated, the degradation of VPA occurs simultaneously with the decomposition of the fibers and catalyzes by forming phosphonic acid, the degradation reaction of the fiber components (especially cellulose) [13,57]. Thus, in the case of VPA, fibers degrade at lower temperatures than in the case of bisphosphonic acids.

The values of total heat release for the different treatments carried out on the miscanthus fibers are represented as a function of the corresponding phosphorus content (Fig. 14). The total heat release of the miscanthus fibers is $9.1 \mathrm{~kJ} / \mathrm{g}$. It increases to $10.6 \mathrm{~kJ} / \mathrm{g}$ after removal of extractives. Extractives can also induce charring due to their composition which contains low molecular weight lignin fractions [33]. The THR of VPA modified miscanthus fibers are lower than those of bisphosphonic acids for similar phosphorus content. For example, when the phosphorus content grafted onto the miscanthus fibers is about $0.9 \mathrm{wt} \%$, the total heat release is $7.9 \mathrm{~kJ} / \mathrm{g}$ when $\mathrm{C} 10$ is grafted while it reaches $6.5 \mathrm{~kJ} / \mathrm{g}$ when the VPA is grafted. Similarly, when the phosphorus content grafted onto the miscanthus fibers is about $1.6 \mathrm{wt} \%$, the
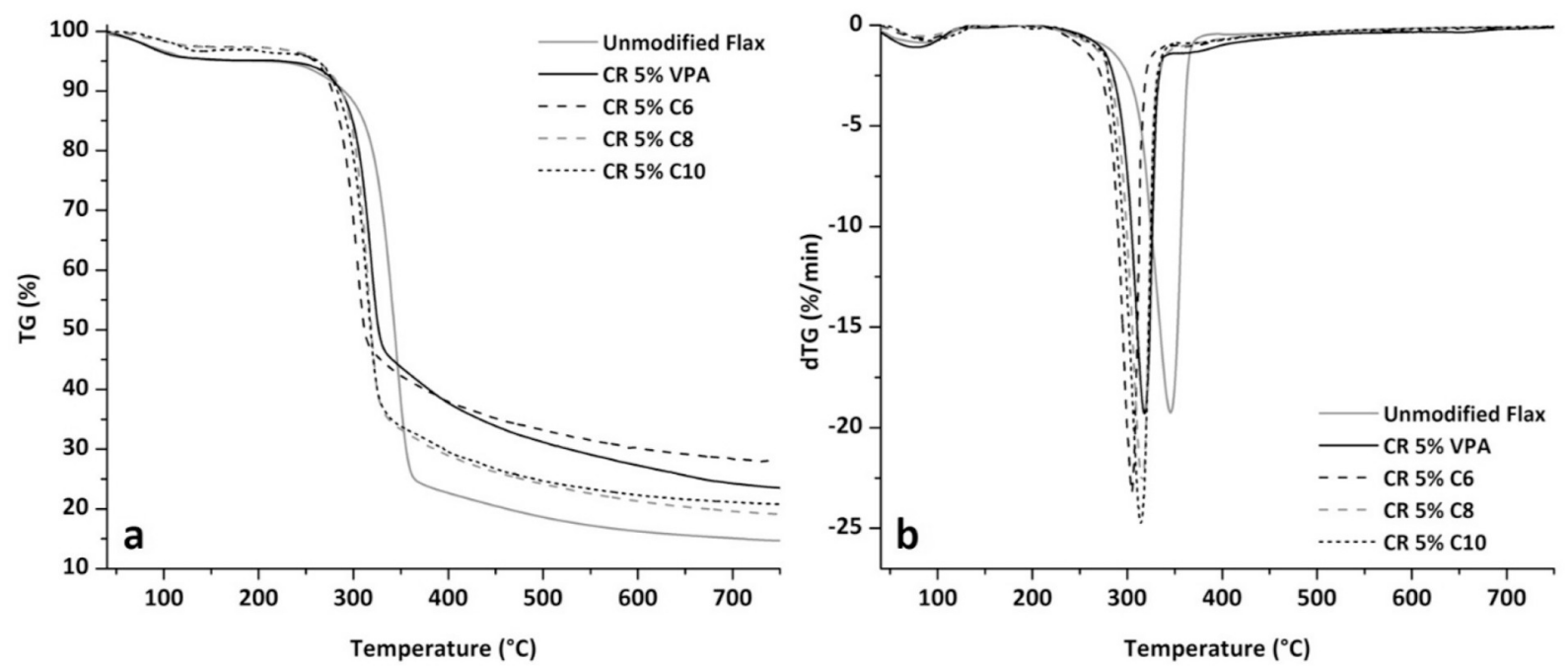

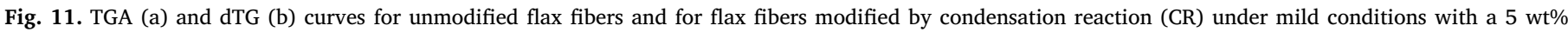
solution of VPA, C6, C8 or C10. 


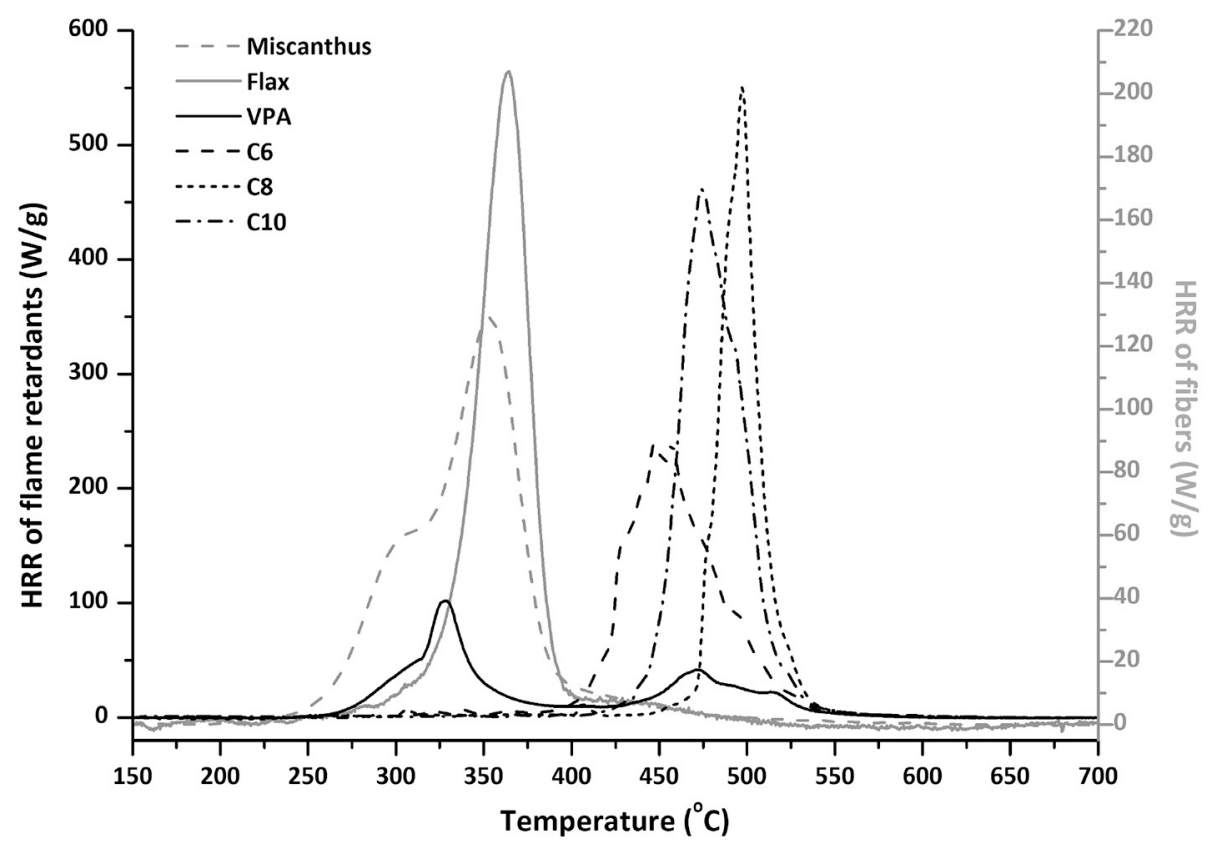

Fig. 12. HRR curves for miscanthus and flax fibers and molecules used for modification.

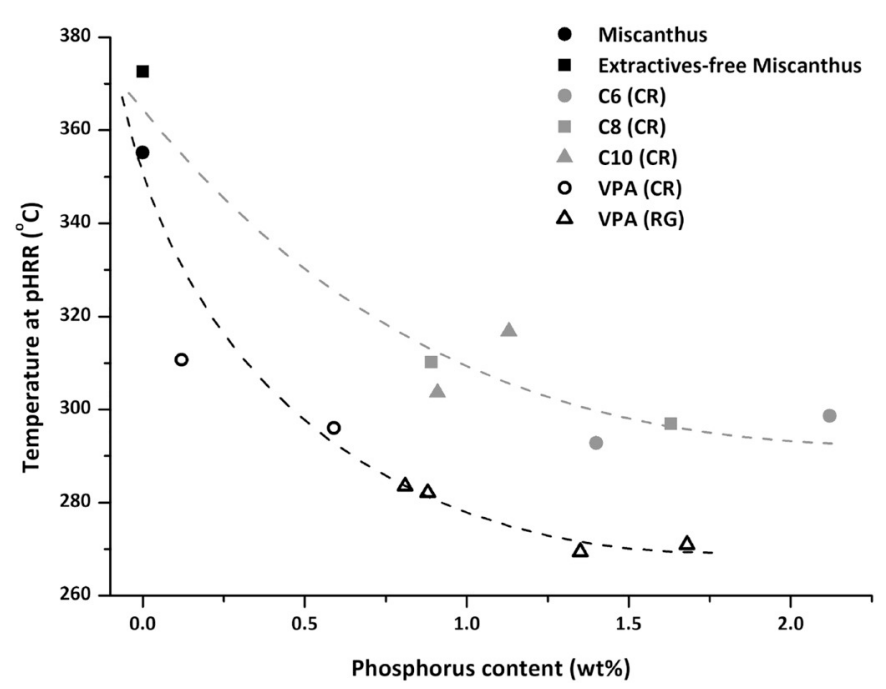

Fig. 13. Variation in pHRR temperature as a function of phosphorus content for miscanthus fibers and those modified by condensation reaction (CR) and radiation grafting (RG) with C6, C8 and C10 bisphosphonic acids and VPA.

total heat release is $6.5 \mathrm{~kJ} / \mathrm{g}$ when $\mathrm{C} 8$ is grafted while it reaches $5.1 \mathrm{~kJ} /$ $\mathrm{g}$ when VPA is grafted. Therefore, the higher thermal stability of these bisphosphonic flame retardants does not allow them to interact efficiently during the decomposition of miscanthus fibers and limits their potential as flame retardants. The total heat released is therefore reduced but in a less important way as in the case of VPA. No matter the grafting procedure, the grafted VPA decomposes simultaneously with the fiber. Then the formation of phosphonic acid due to this VPA degradation promotes the dehydration reaction of the fibers (release of water vapor) and reduces the release of flammable volatile species [13]. Additional explanation is that the THR of VPA is lower than that of bisphosphonic acids (see Table 2). Therefore, the higher THR of fibers modified by bisphosphonic acids (in comparison to VPA) is also partly due to the own contribution of these molecules.

The residue yield after anaerobic pyrolysis (under nitrogen) is measured by thermogravimetric analysis (Fig. 15). The char yield of miscanthus with or without extractives at $750{ }^{\circ} \mathrm{C}$ under inert

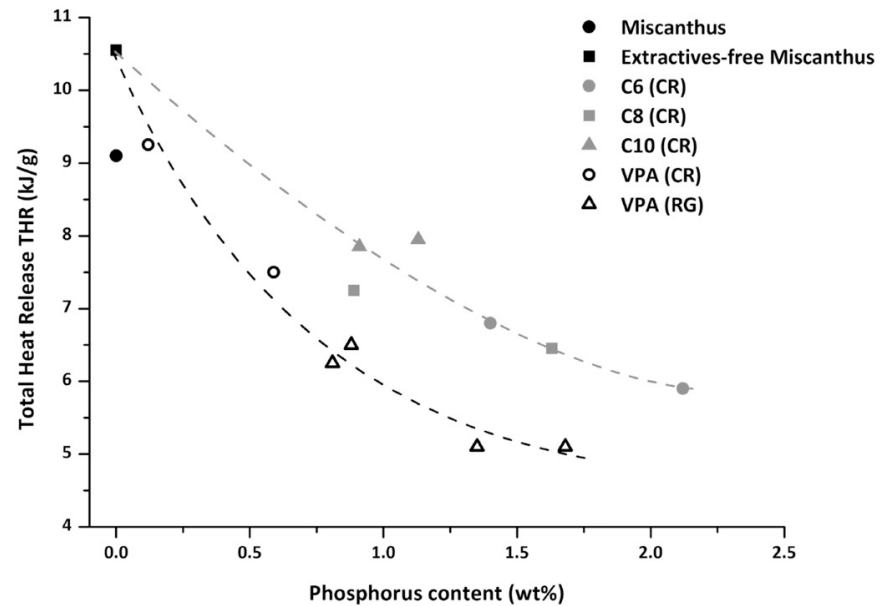

Fig. 14. Variation of total heat release (THR) as a function of phosphorus content for miscanthus fibers and those modified by condensation reaction (CR) and radiation grafting (RG) with $\mathrm{C} 6, \mathrm{C} 8$ and $\mathrm{C} 10$ bisphosphonic acids and VPA.

Table 2

Theoretical total heat release and data obtained by PCFC analyses.

\begin{tabular}{llllll}
\hline Raw Formula & $\begin{array}{l}\Delta \mathrm{H}_{\text {Theoretical }} \\
(\mathrm{kJ} / \mathrm{g})\end{array}$ & $\begin{array}{l}\text { THR } \\
(\mathrm{kJ} / \mathrm{g})\end{array}$ & $\begin{array}{l}\text { pHRR } \\
(\mathrm{W} / \mathrm{g})\end{array}$ & Temperature $\left({ }^{\circ} \mathrm{C}\right)$ \\
\hline VPA & $\mathrm{C}_{2} \mathrm{H}_{5} \mathrm{O}_{3} \mathrm{P}$ & 11.6 & 7.6 & 102 & 327 \\
$\mathrm{C} 6$ & $\mathrm{C}_{6} \mathrm{H}_{16} \mathrm{O}_{6} \mathrm{P}_{2}$ & 16.2 & 14.4 & 240 & 448 \\
$\mathrm{C} 8$ & $\mathrm{C}_{8} \mathrm{H}_{20} \mathrm{O}_{6} \mathrm{P}_{2}$ & 19.1 & 16.3 & 551 & 497 \\
$\mathrm{C} 10$ & $\mathrm{C}_{10} \mathrm{H}_{24} \mathrm{O}_{6} \mathrm{P}_{3}$ & 23.3 & 20.1 & 462 & 474 \\
\hline
\end{tabular}

atmosphere is initially about $27 \mathrm{wt} \%$ which is much higher than for flax, probably due to the higher amount of lignin. The char amount formed after pyrolysis increases with phosphorus content. However, VPA promotes charring of miscanthus fibers better than bisphosphonic acids. For example, char yield reached the same amount around $36 \%$ for less VPA grafted (0.6 wt\% of phosphorus) in comparison to $\mathrm{C} 8 \mathrm{bi}$ sphosphonic acid (1.6 wt \% of phosphorus). Similarly, at almost identical phosphorus contents (about $1.4 \mathrm{wt} \%$ ), the char amount of C6 bisphosphonic acid modified miscanthus fibers is $35 \mathrm{wt} \%$ while that of 


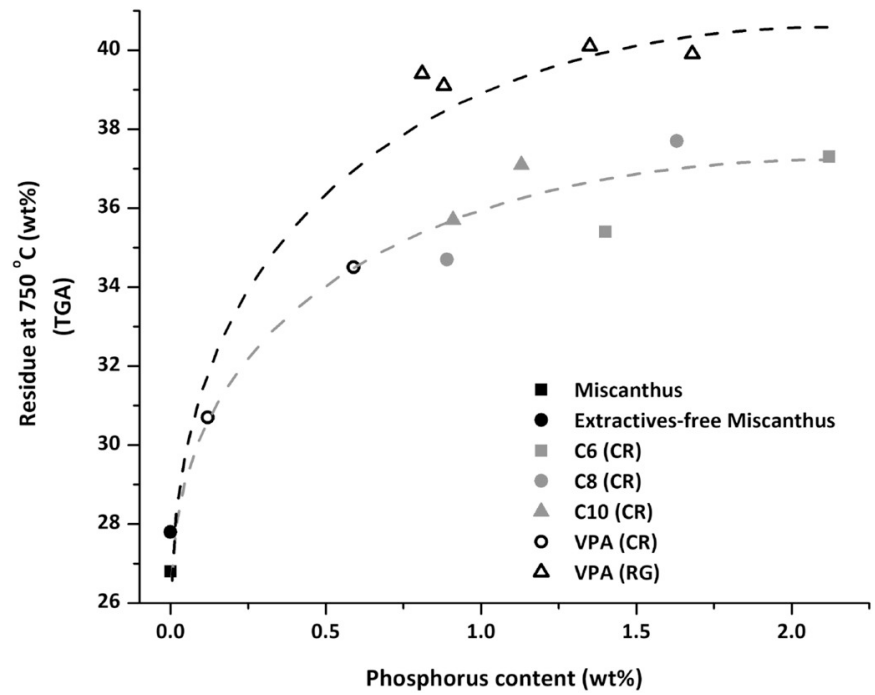

Fig. 15. Variation of the residue percentage at $750{ }^{\circ} \mathrm{C}$ compared to the dry mass of the fibers (anaerobic degradation - TGA) as a function of the phosphorus content for miscanthus fibers and those modified by condensation reaction (CR) and radiation grafting (RG) with $\mathrm{C} 6, \mathrm{C} 8$ and $\mathrm{C} 10$ bisphosphonic acids and VPA.

VPA modified fibers is $40 \mathrm{wt} \%$. These trends observed in thermogravimetric analysis are in good agreement with the results of PCFC.

Fig. 16 compares the total heat release of unmodified and VPA modified flax and MxG fibers. The THR of raw MxG and extractive-free fibers are 9.1 and $10.6 \mathrm{~kJ} / \mathrm{g}$ respectively whereas that of flax fibers is $8.9 \mathrm{~kJ} / \mathrm{g}$. Regardless the modification process, phosphorus grafting seems to be more efficient to improve the fire behavior on flax fabrics than on miscanthus fibers. THR decreases to 6.5 and $3.4 \mathrm{~kJ} / \mathrm{g}$ for miscanthus and flax fibers respectively when phosphorus content reaches around $0.9 \mathrm{wt} \%$. It also decreases to 5.1 and $2.3 \mathrm{~kJ} / \mathrm{g}$ for miscanthus and flax fibers respectively when grafted phosphorus reaches around $1.4 \mathrm{wt} \%$. Those results are in correlation with TGA (Fig. 17) where it is observed that char residue increases more importantly for flax than for miscanthus. Thus, as the char percentage increases, fewer flammable species are released and hence total heat release decreases.

Phosphorylation of lignin-poor fibers seems to be more efficient than phosphorylation of lignin-rich fibers to improve flame retardancy.

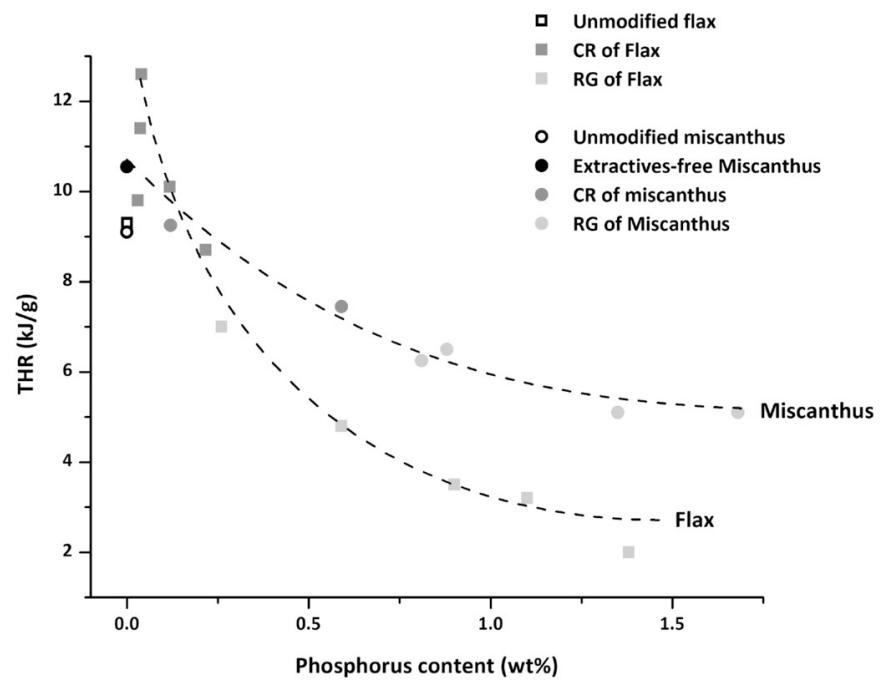

Fig. 16. Variation of total heat release (THR) as a function of phosphorus content for miscanthus and flax fibers modified by condensation reaction (CR) and radiation grafting (RG) with VPA.

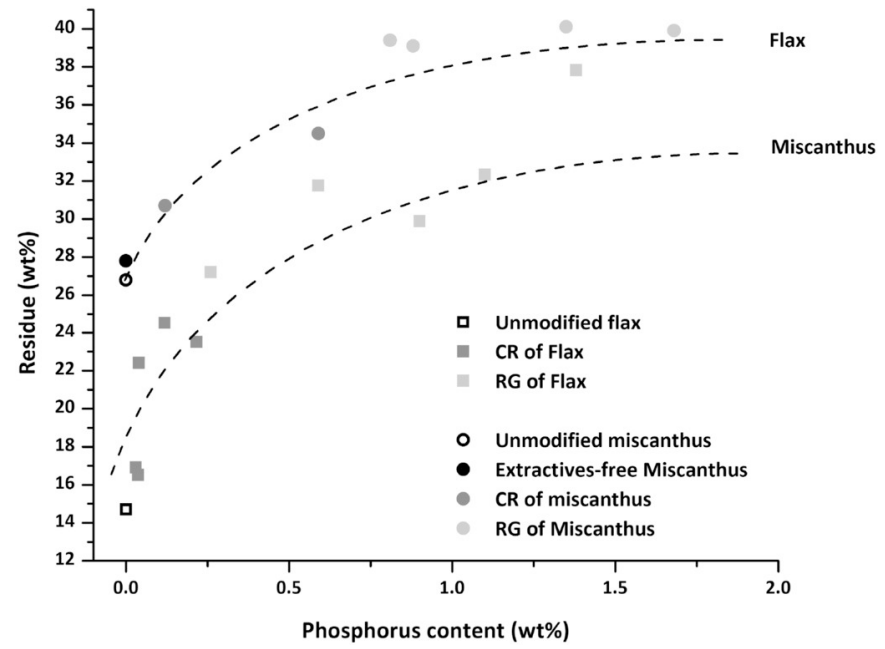

Fig. 17. Variation of residue percentage at $750{ }^{\circ} \mathrm{C}$ (anaerobic degradation TGA) as a function of phosphorus content for miscanthus and flax fibers modified by condensation reaction (CR) and radiation grafting (RG) with VPA.

We suggested in a previous work [20] that phosphorylation of cellulose by chemical modification with VPA in severe conditions decreased the THR of flax by $75 \%$ and increased the char residue (obtained by TGA) by $26 \%$. Nevertheless, Prieur et al. [55] showed that phosphorylation of lignin decreased the THR by $15 \%$ and increased the char by $9 \mathrm{wt} \%$. Other studies show that phosphorylation of lignin particles leads to marginal or no increase in char, probably because lignin is already able to form high amount of char ( $>50 \mathrm{wt} \%$ ) $[53,58]$. Thus, as flax contains more cellulose and less lignin than miscanthus, the flame retardant effect of VPA would be more effective on flax fibers.

\section{Conclusions}

From this study, several conclusions can be drawn:

- Chemical grafting by condensation reaction under mild conditions is more suitable for the modification of lignin-rich fibers (miscanthus, wood, etc.). Thus, the grafting of bisphosphonic acids is more effective on miscanthus than on flax. This is related to the chemical composition of natural fibers (i.e. the lignin content of the fibers).

- Mutual radiation grafting is a modification process that can be applied to all natural fibers whichever the lignin content since the grafting yield is relatively independent on the substrate (similar phosphorus contents were obtained with flax and miscanthus)

- Microscale thermal analyses (TGA, PCFC) show that VPA modified miscanthus fibers release less heat and promote more char than those modified by bisphosphonic acids. Also, VPA modified miscanthus fibers degrade at lower temperatures. The thermal stability of bisphosphonic acids (relatively high compared to miscanthus fibers) does not allow them to act as effective flame retardants at microscale. On the contrary, VPA degrades simultaneously with miscanthus or flax fibers and promotes the charring of the fibers. Thus, the final thermal and flame retardant properties do not only depend on the phosphorus content but also on the thermal stability of the flame retardant. In previous studies [21,22], we did not observe such a result and the charring seemed to be independent of the flame retardant structure but rather related to the phosphorus content only.

- Finally, the char promotion is more efficient for flax than for miscanthus. At high VPA yield obtained by radiografting, THR is significantly lower for flax fibers than for miscanthus. This result confirms that phosphorus is especially efficient for non-aromatic compounds unable to char themselves. 


\section{Acknowledgments}

The authors acknowledge Romain RAVE L and Loïc DUMAZERT, from IMT - Mines Alès for their support on inductively coupled plasma spectrometry and thermal analyses.

\section{Data availability}

The raw/processed data required to reproduce these findings cannot be shared at this time due to technical or time limitations.

\section{Declaration of Competing Interest}

There are no conflicts to declare.

\section{References}

[1] S. Sampaio, D. Bishop, J. Shen, Physical and chemical properties of flax fibres from stand-retted crops desiccated at different stages of maturity, Ind. Crop. Prod. 21 (2005) 275-284, https://doi.org/10.1016/j.indcrop.2004.04.001.

[2] M. Zimniewska, M. Wladyka-Przybylak, S. Rana, R. Fangueiro (Eds.), Natural Fibers for Composite Applications, Springer Singapore, Singapore, 2016, pp. 171-204.

[3] O. Faruk, A.K. Bledzki, H.-P. Fink, M. Sain, Biocomposites reinforced with natural fibers: 2000-2010, Prog. Polym. Sci. 37 (2012) 1552-1596, https://doi.org/10. 1016/j.progpolymsci.2012.04.003.

[4] Y. Li, Q. Li, H. Ma, The voids formation mechanisms and their effects on the mechanical properties of flax fiber reinforced epoxy composites, Compos. Part A Appl. Sci. Manuf. 72 (2015) 40-48, https://doi.org/10.1016/j.compositesa.2015.01.029.

[5] D. Puglia, J. Biagiotti, J.M. Kenny, A review on natural fibre-based composites-part II, J. Nat. Fibers. 1 (2005) 23-65, https://doi.org/10.1300/J395v01n03_03.

[6] J. Biagiotti, D. Puglia, J.M. Kenny, A review on natural fibre-based composites-part I, J. Nat. Fibers. 1 (2004) 37-68, https://doi.org/10.1300/J395v01n02_04.

[7] L. Yan, B. Kasal, L. Huang, A review of recent research on the use of cellulosic fibres, their fibre fabric reinforced cementitious, geo-polymer and polymer composites in civil engineering, Compos. Part B Eng. 92 (2016) 94-132, https://doi.org/10.1016/ j.compositesb.2016.02.002.

[8] A.K. Bledzki, J. Gassan, Composites reinforced with cellulose based fibres, Prog. Polym. Sci. 24 (1999) 221-274, https://doi.org/10.1016/S0079-6700(98)00018-5.

[9] M. JOHN, S. THOMAS, Biofibres and biocomposites, Carbohydr. Polym. 71 (2008) 343-364, https://doi.org/10.1016/j.carbpol.2007.05.040.

[10] M.E. Mngomezulu, M.J. John, V. Jacobs, A.S. Luyt, Review on flammability of biofibres and biocomposites, Carbohydr. Polym. 111 (2014) 149-182, https://doi. org/10.1016/j.carbpol.2014.03.071

[11] S. Chapple, R. Anandjiwala, Flammability of natural Fiber-reinforced composites and strategies for fire Retardancy: a review, J. Thermoplast. Compos. Mater. 23 (2010) 871-893, https://doi.org/10.1177/0892705709356338.

[12] N.P.G. Suardana, M.S. Ku, J.K. Lim, Effects of diammonium phosphate on the flammability and mechanical properties of bio-composites, Mater. Des. 32 (2011) 1990-1999, https://doi.org/10.1016/j.matdes.2010.11.069.

[13] A.R. Horrocks, An introduction to the burning behaviour of cellulosic Fibres, J. Soc. Dye. Colour. 99 (2008) 191-197, https://doi.org/10.1111/j.1478-4408.1983. tb03686.x.

[14] R.M. Kozlowski, M. Mackiewicz-Talarczyk, J. Barriga-Bedoya, Natural fibers production, processing, and application: inventory and future prospects, Contemp. Sci. Polym. Mater, American Chemical Society, 2010, pp. 41-51.

[15] K. Opwis, A. Wego, T. Bahners, E. Schollmeyer, Permanent flame retardant finishing of textile materials by a photochemical immobilization of vinyl phosphonic acid, Polym. Degrad. Stab. 96 (2011) 393-395, https://doi.org/10.1016/j polymdegradstab. 2010.02.022.

[16] M. Parvinzadeh Gashti, A. Almasian, UV radiation induced flame retardant cellulose fiber by using polyvinylphosphonic acid/carbon nanotube composite coating, Compos. Part B Eng. 45 (2013) 282-289, https://doi.org/10.1016/j.compositesb. 2012.07.052.

[17] K. Williams, J.R. Ebdon, B.K. Kandola, Intumescent fire-retardant coatings for plastics based on poly(vinylphosphonic acid): improving water resistance with comonomers, J. Appl. Polym. Sci. 137 (2019) 47601, https://doi.org/10.1002/app. 47601.

[18] M.J. Tsafack, J. Levalois-Grützmacher, Towards multifunctional surfaces using the plasma-induced graft-polymerization (PIGP) process: flame and waterproof cotton textiles, Surf. Coat. Technol. 201 (2007) 5789-5795, https://doi.org/10.1016/j. surfcoat.2006.10.027.

[19] J. Alongi, M. Ciobanu, G. Malucelli, Sol-gel treatments for enhancing flame retardancy and thermal stability of cotton fabrics: optimisation of the process and evaluation of the durability, Cellulose. 18 (2011) 167-177, https://doi.org/10. 1007/s10570-010-9470-2.

[20] R. Hajj, R. El Hage, R. Sonnier, B. Otazaghine, B. Gallard, S. Rouif, M. Nakhl, J.M. Lopez-Cuesta, Grafting of phosphorus flame retardants on flax fabrics: comparison between two routes, Polym. Degrad. Stab. 147 (2018) 25-34, https://doi org/10.1016/j.polymdegradstab. 2017.11.006

[21] R. Hajj, B. Otazaghine, R. Sonnier, R. El Hage, S. Rouif, M. Nakhl, J.-M. Lopez-
Cuesta, Influence of monomer reactivity on radiation grafting of phosphorus flame retardants on flax fabrics, Polym. Degrad. Stab. 166 (2019) 86-98, https://doi.org/ 10.1016/j.polymdegradstab. 2019.05.025.

[22] R. Sonnier, B. Otazaghine, A. Viretto, G. Apolinario, P. Ienny, Improving the flame retardancy of flax fabrics by radiation grafting of phosphorus compounds, Eur. Polym. J. 68 (2015) 313-325, https://doi.org/10.1016/j.eurpolymj.2015.05.005.

[23] M. Teixeira, R. Sonnier, B. Otazaghine, L. Ferry, M. Aubert, T. Tirri, C.-E. Wilén, S. Rouif, Radiation-grafting of flame retardants on flax fabrics - a comparison between different flame retardant structures, Radiat. Phys. Chem. 145 (2018) 135-142, https://doi.org/10.1016/j.radphyschem.2017.10.013.

[24] J.A. Harris, J.C. Arthur, W.R. Goynes, Flame resistant cotton fabrics prepared by radiation-initiated polymerization with vinyl phosphonate oligomer and N-methylolacrylamide, J. Appl. Polym. Sci. 23 (1979) 2555-2565, https://doi.org/10.1002/ app.1979.070230902.

[25] E. El Kassis, B. Otazaghine, R. El Hage, R. Sonnier, Assessment of olive pomace wastes as flame retardants, J. Appl. Polym. Sci. 137 (2020) 47715, https://doi.org/ 10.1002/app. 47715.

[26] S. Ben Abdallah, M. Teixeira, I. Chala, B. Otazaghine, R. Sonnier, C. Longuet, J.C. Roux, S. Rouif, Chemical treatments of flax fibers - control of the diffusion of molecules into the fiber structure, Ind. Crop. Prod. 132 (2019) 430-439, https:// doi.org/10.1016/j.indcrop.2019.02.041.

[27] N. Le Moigne, R. Sonnier, R. El Hage, S. Rouif, Radiation-induced modifications in natural fibres and their biocomposites: opportunities for controlled physico-chemical modification pathways? Ind. Crop. Prod. 109 (2017) 199-213, https://doi. org/10.1016/j.indcrop.2017.08.027.

[28] G. Dorez, B. Otazaghine, A. Taguet, L. Ferry, J.M. Lopez-Cuesta, Use of Py-GC/MS and PCFC to characterize the surface modification of flax fibres, J. Anal. Appl. Pyrolysis 105 (2014) 122-130, https://doi.org/10.1016/j.jaap.2013.10.011.

[29] J. Sharif, S.F. Mohamad, N.A. Fatimah Othman, N.A. Bakaruddin, H.N. Osman, O. Güven, Graft copolymerization of glycidyl methacrylate onto delignified kenaf fibers through pre-irradiation technique, Radiat. Phys. Chem. 91 (2013) 125-131, https://doi.org/10.1016/j.radphyschem.2013.05.035.

[30] N.H. Mohamed, M. Tamada, Y. Ueki, N. Seko, Effect of partial delignification of kenaf bast fibers for radiation graft copolymerization, J. Appl. Polym. Sci. 127 (2012) 2891-2895, https://doi.org/10.1002/app.37512.

[31] E.M. Hodgson, D.J. Nowakowski, I. Shield, A. Riche, A.V. Bridgwater, J.C. CliftonBrown, I.S. Donnison, Variation in Miscanthus chemical composition and implications for conversion by pyrolysis and thermo-chemical bio-refining for fuels and chemicals, Bioresour. Technol. 102 (2011) 3411-3418, https://doi.org/10.1016/j. biortech.2010.10.017.

[32] E. Alexopoulou, M. Christou, I. Eleftheriadis, Role of 4F Cropping in Determining Future Biomass Potentials, Including Sustainability and Policy Related Issues, https://www.semanticscholar.org/paper/Role-of-4F-cropping-in-determiningfuture-biomass-Alexopoulou-Christou/ a8a248e758e6ffb891fb1b9219e50d70463915a7\#citing-papers, (2010).

[33] N. Brosse, R. El Hage, P. Sannigrahi, A. Ragauskas, Dilute sulphuric acid and ethanol organosolv pretreatment of miscanthus x giganteus, Cellul. Chem. Technol $44(1-3)(2010) 71-78$.

[34] R. El, P. Sannigrahi, A. Ragauskas, Biofuels and Biomaterials from Miscanthus x Giganteus, NWBC, Helsinki, 2009, pp. 9-13.

[35] R. El Hage, N. Brosse, P. Navarrete, A. Pizzi, Extraction, characterization and utilization of organosolv miscanthus lignin for the conception of environmentally friendly mixed tannin/lignin wood resins, J. Adhes. Sci. Technol. 25 (2011) 1549-1560, https://doi.org/10.1163/016942410X524110.

[36] R. El Hage, N. Brosse, P. Sannigrahi, A. Ragauskas, Effects of process severity on the chemical structure of Miscanthus ethanol organosolv lignin, Polym. Degrad. Stab. 95 (2010) 997-1003, https://doi.org/10.1016/j.polymdegradstab. 2010.03.012.

[37] R. El Hage, D. Perrin, N. Brosse, Effect of the pre-treatment severity on the antioxidant properties of ethanol organosolv miscanthus $\mathrm{x}$ giganteus lignin, Nat. Resour. 3 (2012) 29-34, https://doi.org/10.4236/nr.2012.32005.

[38] R. El Hage, L. Chrusciel, L. Desharnais, N. Brosse, Effect of autohydrolysis of Miscanthus $\mathrm{x}$ giganteus on lignin structure and organosolv delignification, Bioresour. Technol. 101 (2010) 9321-9329, https://doi.org/10.1016/j.biortech. 2010.06.143.

[39] R. El Hage, N. Brosse, L. Chrusciel, C. Sanchez, P. Sannigrahi, A. Ragauskas, Characterization of milled wood lignin and ethanol organosolv lignin from miscanthus, Polym. Degrad. Stab. 94 (2009) 1632-1638, https://doi.org/10.1016/j. polymdegradstab. 2009.07.007.

[40] L. Ping, R.E.L. Hage, A. Pizzi, Z.D. Guo, N. Brosse, Extraction of polyphenolics from lignocellulosic materials and agricultural byproducts for the formulation of resin for wood adhesives, J. Biobased Mater. Bioenergy. 5 (2011) 460-465, https://doi.org/ 10.1166/jbmb.2011.1172.

[41] R. El Hage, Y. Khalaf, C. Lacoste, M. Nakhl, P. Lacroix, A. Bergeret, A flame retarded chitosan binder for insulating miscanthus/recycled textile fibers reinforced biocomposites, J. Appl. Polym. Sci. 136 (2019) 47306, https://doi.org/10.1002/app. 47306.

[42] [dataset] T.A. of the P. and P.I, (TAPPI), T-264 om-97, Preparation of Wood for Chemical Analysis, (2007).

[43] O. Theander, Chemical analysis of lignocellulose materials, Anim. Feed Sci. Technol. 32 (1991) 35-44, https://doi.org/10.1016/0377-8401(91)90007-F.

[44] C. Huggett, Estimation of rate of heat release by means of oxygen consumption measurements, Fire Mater. 4 (1980) 61-65, https://doi.org/10.1002/fam. 810040202.

[45] D.M. Smith, R.Y. Mixer, The effects of lignin on the degradation of wood by gamma irradiation, Radiat. Res. 11 (1959) 776, https://doi.org/10.2307/3570716.

[46] V. Melina, Smoke Point of Oils, 2012. https://www.veghealth.com/nutrition- 
tables/Smoke-Points-of-Oils-table.pd. (visited on August 2018).

[47] G. Dorez, L. Ferry, R. Sonnier, A. Taguet, J.-M. Lopez-Cuesta, Effect of cellulose, hemicellulose and lignin contents on pyrolysis and combustion of natural fibers, J. Anal. Appl. Pyrolysis 107 (2014) 323-331, https://doi.org/10.1016/j.jaap.2014. 03.017.

[48] O. Egyed, J. Simon, Investigations on the flame-retardation of cellulosic fibrous materials, J. Therm. Anal. 16 (1979) 307-320, https://doi.org/10.1007/ BF01910694.

[49] S. Gaan, G. Sun, Effect of phosphorus and nitrogen on flame retardant cellulose: a study of phosphorus compounds, J. Anal. Appl. Pyrolysis 78 (2007) 371-377, https://doi.org/10.1016/j.jaap.2006.09.010.

[50] A.C. Fernandez-Pello, T. Hirano, Controlling mechanisms of flame spread, Combust. Sci. Technol. 32 (1983) 1-31, https://doi.org/10.1080/00102208308923650.

[51] E.D. Weil, S.V. Levchik, Flame Retardants for plastics and textiles, Flame Retard. Plast. Text, Carl Hanser Verlag, München, 2009pp. I-XVIII.

[52] S. Liodakis, I.K. Fetsis, I.P. Agiovlasitis, The fire-retarding effect of inorganic phosphorus compounds on the combustion of cellulosic materials, J. Therm. Anal. Calorim. 98 (2009) 285-291, https://doi.org/10.1007/s10973-009-0307-x.

[53] D.J. Nowakowski, C.R. Woodbridge, J.M. Jones, Phosphorus catalysis in the pyrolysis behaviour of biomass, J. Anal. Appl. Pyrolysis 83 (2008) 197-204, https://doi.org/10.1016/j.jaap.2008.08.003.

[54] B. Prieur, M. Meub, M. Wittemann, R. Klein, S. Bellayer, G. Fontaine, S. Bourbigot, Phosphorylation of lignin to flame retard acrylonitrile butadiene styrene (ABS), Polym. Degrad. Stab. 127 (2016) 32-43, https://doi.org/10.1016/j. polymdegradstab. 2016.01.015.

[55] B. Prieur, M. Meub, M. Wittemann, R. Klein, S. Bellayer, G. Fontaine, S. Bourbigot, Phosphorylation of lignin: characterization and investigation of the thermal decomposition, RSC Adv. 7 (2017) 16866-16877, https://doi.org/10.1039/ C7RA00295E.

[56] G.L. Bykov, B.G. Ershov, A sorbent based on phosphorylated lignin, Russ. J. Appl. Chem. 83 (2010) 316-319, https://doi.org/10.1134/S1070427210020254.

[57] D. Price, L.K. Cunliffe, K.J. Bullet, T.R. Hull, G.J. Milnes, J.R. Ebdon, B.J. Hunt, P. Joseph, Thermal behavior of covalently bonded phosphonate flame-retarded poly (methyl methacrylate) systems, Polym. Adv. Technol. 19 (2008) 710-723, https:// doi.org/10.1002/pat.1167.

[58] B. Chollet, J.-M. Lopez-Cuesta, F. Laoutid, L. Ferry, Lignin nanoparticles as a promising way for enhancing lignin flame retardant effect in Polylactide, Materials. 12 (2019) 2132, https://doi.org/10.3390/ma12132132. 